\title{
Therapeutic Opioids: A Ten-Year Perspective on the Complexities and Complications of the Escalating Use, Abuse, and Nonmedical Use of Opioids
}

From: ${ }^{1}$ Pain Management Center of Paducah, KY; and ${ }^{2}$ Pain Diagnostic Associates, Niagara, WI

Dr. Manchikanti is Medical Director of the Pain Management Center of Paducah, Paducah, KY, and Associate

Clinical Professor of Anesthesiology and Perioperative Medicine, University of Louisville, Louisville, KY.

Ms. Singh is Research Assistant, Pain Diagnostic Associates, Niagara, WI.

Address correspondence: Laxmaiah Manchikanti, MD 2831 Lone Oak Road Paducah, Kentucky 42003 E-mail:drlm@thepainmd.com

Disclaimer: There was no external funding in the preparation of this manuscript.

Conflict of interest: None.

Free full manuscript: www.painphysicianjournal.com
Therapeutic opioid use and abuse coupled with the nonmedical use of other psychotherapeutic drugs has shown an explosive growth in recent years and has been a topic of great concern and controversy. Americans, constituting only $4.6 \%$ of the world's population, have been consuming $80 \%$ of the global opioid supply, and $99 \%$ of the global hydrocodone supply, as well as two-thirds of the world's illegal drugs. With the increasing therapeutic use of opioids, the supply and retail sales of opioids are mirrored by increasing abuse in patients receiving opioids, nonmedical use of other psychotherapeutic drugs (in this article the category of psychotherapeutics includes pain relievers, tranquilizers, stimulants, and sedatives, but does not include over-the-counter drugs), emergency department visits for prescription controlled drugs, exploding costs, increasing incidence of side effects, and unintentional deaths.

However, all these ills of illicit drug use and opioid use, abuse, and non-medical use do not stop with adults. It has been shown that $80 \%$ of America's high school students, or 11 million teens, and $44 \%$ of middle school students, or 5 million teens, have personally witnessed, on the grounds of their schools, illegal drug use, illegal drug dealing, illegal drug possession, and other activities related to drug abuse.

The results of the 2006 National Survey on Drug Use and Health showed that 7.0 million or $2.8 \%$ of all persons aged 12 or older had used prescription type psychotherapeutic drugs nonmedically in the past month, 16.387 million, or $6.6 \%$ of the population, had used in the past year, and $20.3 \%$, or almost 49.8 million, had used prescription psychotherapeutic drugs nonmedically during their lifetime. Sadly, the initiates of psychotherapeutic drugs used for nonmedical purposes were highest for opioids.

Therapeutic opioid use has increased substantially, specifically of Schedule II drugs. Apart from lack of effectiveness (except for short-term, acute pain) there are multiple adverse consequences including hormonal and immune system effects, abuse and addiction, tolerance, and hyperalgesia. Patients on long-term opioid use have been shown to increase the overall cost of healthcare, disability, rates of surgery, and late opioid use.

Key words: Controlled prescription drug abuse, opioid abuse, opioid misuse, nonmedical use of psychotherapeutic drugs, nonmedical use of opioids, National Survey on Drug Use and Health, National Center on Addiction and Substance Abuse at Columbia University

Pain Physician 2008; Opioid Special Issue: 11:S63-S88 
D ased largely upon the 2006 National Survey on Drug Use and Health (1) and a review of the current literature, this article describes a 10-year perspective on the complex and complicated interrelationships between the therapeutic use of opioids and other psychotherapeutics and the consequences of escalating use, abuse, and nonmedical use as it affects this nation's problems of substance abuse, mental health, disability, and our ailing healthcare system.

For the last several years in the United States, the treatment of chronic pain, therapeutic opioid use and abuse, and the nonmedical use of prescription drugs have been topics of intense focus and controversy (27). Due in some measure to the campaign of alleged undertreatment of pain, Americans, constituting only $4.6 \%$ of the world's population, have been consuming $80 \%$ of the global opioid supply, and $99 \%$ of the global hydrocodone supply, as well as two-thirds of the world's illegal drugs (2-5,8-10). Retail sales of opioid medications have increased from a total in 1997 of 50.7 million grams of commonly utilized opioids (including methadone, oxycodone, fentanyl base, hydromorphone, hydrocodone, morphine, meperidine, and codeine) to 115.3 million grams in 2006, an overall increase of $127 \%$ with increases ranging from $196 \%$ for morphine, $244 \%$ for hydrocodone, $274 \%$ for hydromorphone, $479 \%$ for fentanyl base, $732 \%$ for oxycodone, to $1177 \%$ for methadone (11). In 2005 and 2006, over 120 million prescriptions for hydrocodone were issued and hydrocodone continues to be the number one prescribed drug in the United States $(3,4,9,11,12)$. Average sales of opioids per person have increased from 74 milligrams in 1997 to 329 milligrams in 2006, a $347 \%$ increase. It is no surprise then that surveys of nonprescription drug abuse $(1,13-17)$, emergency department visits for prescription controlled drugs (18-22), unintentional deaths due to prescription controlled substances (23-31), therapeutic use of opioids, and opioid abuse (32-88) have been steadily rising.

The National Survey of American Attitudes on Substance Abuse XII: Teens and Parents (89) shows $80 \%$ of America's high school students, or 11 million teens, and $44 \%$ of America's middle school students, or 5 million teens, have personally witnessed, on the grounds of their schools, illegal drug use, illegal drug dealing, illegal drug possession, students drunk, and/ or students high on drugs. It must be remembered that illegal is synonymous with illicit and includes drugs such as marijuana/hashish, cocaine (including crack), heroin, hallucinogens, and inhalants as well as the nonmedical use of prescription drugs, which is also illicit and illegal.

This survey (89) also revealed that compared to teens at drug-free schools, teens at drug-infested schools are 16 times likelier to use an illegal drug other than marijuana or prescription drugs, 15 times likelier to abuse prescription drugs, 6 times likelier to get drunk at least once a month, and 5 times likelier to use marijuana. Sadly, since 2002 the proportion of students who attend schools where drugs are used, kept, or sold has jumped $39 \%$ for high school students and $63 \%$ for middle school students. What is also clear from this survey is that physicians' well intentioned, appropriate, and legitimate prescriptions are, at an alarmingly increasing rate, being tragically diverted for nonmedical use not only by adults, but also by high school and middle school students. We must now closely examine these unintended consequences.

\section{Non-medical Use of Psychotherapeutic Drugs}

Results of the 2006 National Survey on Drug Use and Health (NSDUH) (1), an annual survey sponsored by the Substance Abuse and Mental Health Services Administration (SAMHSA), showed that an estimated 20.4 million, or $8.3 \%$ of Americans, aged 12 or older, were current (past month) illicit drug users. Illicit drugs include marijuana/hashish, cocaine, heroin, hallucinogens, inhalants, or prescription-type psychotherapeutics (defined in this survey as prescription-type pain relievers, tranquilizers, stimulants, and sedatives) used nonmedically. Marijuana and Hashish were the most commonly used illicit drugs with 14.8 million current (past month) users, or $6 \%$ of the US population. Cocaine was used by 2.4 million, whereas hallucinogens were used in the past month by 1 million persons (Table 1 and Fig. 1). Next to marijuana, 7.0 million (2.8\%) persons aged 12 or older had used prescription-type psychotherapeutic drugs nonmedically in the past month (current use). Of these, 5.2 million had used pain relievers, an increase from 4.7 million in 2005. The category of psychotherapeutics used in the tables and figures includes the nonmedical use of any prescription-type pain relievers, tranquilizers, stimulants, or sedatives. However, over-the-counter substances are not included in these studies. The categories of nonmedical use of psychotherapeutics and pain relievers 


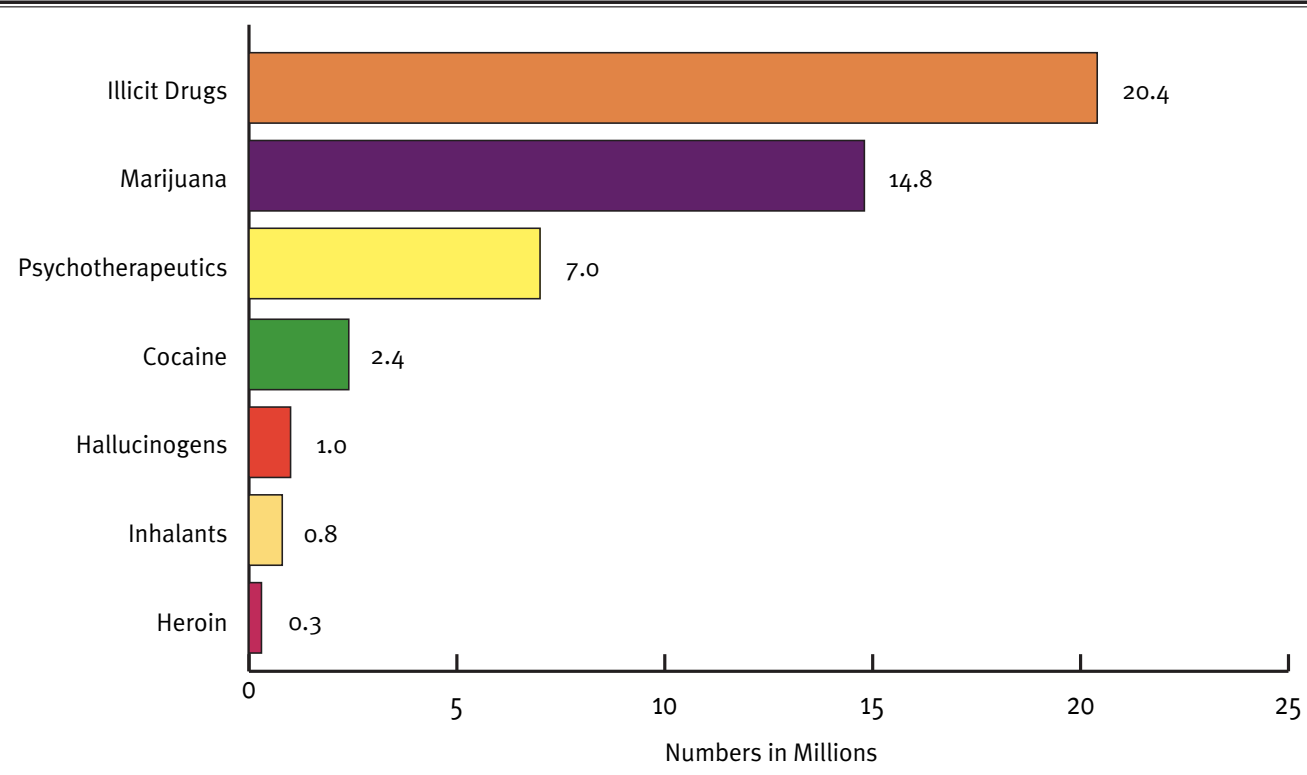

Fig. 1. Past month use of specific illicit drugs among persons aged 12 or older: 2006 (1).

Source: www.oas.samhsa.gov/nsduh/2k6nsduh/2k6results.pdf

Table 1. Types of illicit drug use in the past month among persons aged 12 or older: Numbers in thousands, from 1997 to 2006 (10 years).

\begin{tabular}{|c|c|c|c|c|c|c|c|c|c|c|c|}
\hline Drugs & 1997 & 1998 & 1999 & 2000 & 2001 & 2002 & 2003 & 2004 & 2005 & 2006 & $\begin{array}{c}\text { 10-YEAR } \\
\% \text { change } \\
\text { from } 1997 \\
\text { to } 2006\end{array}$ \\
\hline $\begin{array}{l}\text { Nonmedical Use of } \\
\text { Psychotherapeutics }\end{array}$ & $\begin{array}{l}2,665 \\
(1.2 \%)\end{array}$ & $\begin{array}{l}2,477 \\
(1.1 \%)\end{array}$ & $\begin{array}{l}3,952 \\
(1.8 \%)\end{array}$ & $\begin{array}{r}3,849 \\
(1.7 \%)^{\prime}\end{array}$ & $\begin{array}{l}4,811^{\mathrm{c}} \\
(2.1 \%)\end{array}$ & $\begin{array}{l}6,210^{\mathrm{a}} \\
(2.6 \%)\end{array}$ & $\begin{array}{l}6,336 \\
(2.7 \%)\end{array}$ & $\begin{array}{l}6,007^{\mathrm{b}} \\
\left(2.5 \%^{\mathrm{b}}\right)\end{array}$ & $\begin{array}{l}6,405 \\
(2.6 \%)\end{array}$ & $\begin{array}{l}6,991 \\
(2.8 \%)\end{array}$ & $162 \%$ \\
\hline Pain Relievers & -- & -- & $\begin{array}{l}2,621 \\
(1.2 \%)\end{array}$ & $\begin{array}{l}2,782 \\
(1.2 \%)\end{array}$ & $\begin{array}{l}3,497^{c} \\
(1.6 \%)\end{array}$ & $\begin{array}{l}4,377^{\mathrm{b}} \\
\left(1.9 \%^{\mathrm{a}}\right)\end{array}$ & $\begin{array}{c}4,693 \\
(2.0 \%)\end{array}$ & $\begin{array}{l}4,404^{\mathrm{b}} \\
\left(1.8 \%^{\mathrm{a}}\right)\end{array}$ & $\begin{array}{l}4,658^{\mathrm{a}} \\
(1.9 \%)\end{array}$ & $\begin{array}{l}5,220 \\
(2.1 \%)\end{array}$ & NA \\
\hline OxyContin ${ }^{\circ}$ & -- & -- & -- & -- & -- & -- & -- & $\begin{array}{c}325 \\
(0.1 \%) \\
\end{array}$ & $\begin{array}{c}334 \\
(0.1 \%)\end{array}$ & $\begin{array}{c}276 \\
(0.1 \%) \\
\end{array}$ & NA \\
\hline Tranquilizers & $\begin{array}{c}845 \\
(0.4 \%)\end{array}$ & $\begin{array}{c}655 \\
(0.3 \%)\end{array}$ & $\begin{array}{l}1,097 \\
(0.5 \%)\end{array}$ & $\begin{array}{l}1,000 \\
(0.4 \%)\end{array}$ & $\begin{array}{l}1,358^{\mathrm{c}} \\
(0.6 \%)\end{array}$ & $\begin{array}{l}1,804 \\
(0.8 \%)\end{array}$ & $\begin{array}{l}1,830 \\
(0.8 \%)\end{array}$ & $\begin{array}{l}1,616 \\
(0.7 \%)\end{array}$ & $\begin{array}{l}1,817 \\
(0.7 \%)\end{array}$ & $\begin{array}{l}1,766 \\
(0.7 \%)\end{array}$ & $109 \%$ \\
\hline Stimulants & $\begin{array}{c}612 \\
(0.3 \%)\end{array}$ & $\begin{array}{c}633 \\
(0.3 \%)\end{array}$ & $\begin{array}{c}950 \\
(0.4 \%)\end{array}$ & $\begin{array}{c}788 \\
(0.4 \%)\end{array}$ & $\begin{array}{l}1,018 \\
(0.5 \%)\end{array}$ & $\begin{array}{l}1,218 \\
(0.5 \%)\end{array}$ & $\begin{array}{l}1,191 \\
(0.5 \%)\end{array}$ & $\begin{array}{c}1,189 \\
(0.5 \%)\end{array}$ & $\begin{array}{l}1,067 \\
(0.4 \%)\end{array}$ & $\begin{array}{c}1,191 \\
(0.5 \%)\end{array}$ & $95 \%$ \\
\hline Sedatives & $\begin{array}{c}187 \\
(0.1 \%)\end{array}$ & $\begin{array}{c}210 \\
(0.1 \%)\end{array}$ & $\begin{array}{c}229 \\
(0.1 \%)\end{array}$ & $\begin{array}{c}175 \\
(0.1 \%)\end{array}$ & $\begin{array}{c}306 \\
(0.1 \%)\end{array}$ & $\begin{array}{c}436 \\
(0.2 \%)\end{array}$ & $\begin{array}{c}294 \\
(0.1 \%)\end{array}$ & $\begin{array}{c}265 \\
(0.1 \%)\end{array}$ & $\begin{array}{c}272 \\
(0.1 \%)\end{array}$ & $\begin{array}{c}385 \\
(0.2 \%)\end{array}$ & $106 \%$ \\
\hline $\begin{array}{l}\text { Marijuana and } \\
\text { Hashish }\end{array}$ & $\begin{array}{l}11,109 \\
(5.1 \%)\end{array}$ & $\begin{array}{l}11,016 \\
(5.0 \%)\end{array}$ & $\begin{array}{l}10,458 \\
(4.7 \%)\end{array}$ & $\begin{array}{c}10,714 \\
(4.8)\end{array}$ & $\begin{array}{l}12,122^{c} \\
(5.4 \%)\end{array}$ & $\begin{array}{l}14,584 \\
(6.2 \%)\end{array}$ & $\begin{array}{l}14,638 \\
(6.2 \%)\end{array}$ & $\begin{array}{l}14,576 \\
(6.1 \%)\end{array}$ & $\begin{array}{l}14,626 \\
(6.0 \%)\end{array}$ & $\begin{array}{l}14,813 \\
(6.0 \%)\end{array}$ & $33 \%$ \\
\hline Cocaine & $\begin{array}{l}1,505 \\
(0.7 \%)\end{array}$ & $\begin{array}{l}1,750 \\
(0.8 \%)\end{array}$ & $\begin{array}{c}1,552 \\
(0.7 \%)\end{array}$ & $\begin{array}{l}1,213 \\
(0.5 \%)\end{array}$ & $\begin{array}{l}1,667^{c} \\
(0.7 \%)\end{array}$ & $\begin{array}{l}2,020^{\mathrm{a}} \\
(0.9 \%)\end{array}$ & $\begin{array}{l}2,281 \\
(1.0 \%)\end{array}$ & $\begin{array}{l}2,021^{\mathrm{a}} \\
(0.8 \%)\end{array}$ & $\begin{array}{l}2,397 \\
(1.0 \%)\end{array}$ & $\begin{array}{c}2,421 \\
(1.0 \%)\end{array}$ & $61 \%$ \\
\hline $\begin{array}{l}\text { TOTAL } \\
\text { ILLICIT DRUGS }^{1}\end{array}$ & $\begin{array}{l}13,904 \\
(6.4 \%)\end{array}$ & $\begin{array}{l}13,615 \\
(6.2 \%)\end{array}$ & $\begin{array}{l}13,829 \\
(6.3 \%)\end{array}$ & $\begin{array}{l}14,027 \\
(6.3 \%)\end{array}$ & $\begin{array}{l}15,910^{c} \\
(7.1 \%)\end{array}$ & $\begin{array}{l}19,522 \\
(8.3 \%)\end{array}$ & $\begin{array}{l}19,470 \\
(8.2 \%)\end{array}$ & $\begin{array}{l}19,071^{\mathrm{a}} \\
(7.9 \%)\end{array}$ & $\begin{array}{l}19,720 \\
(8.1 \%)\end{array}$ & $\begin{array}{l}20,357 \\
(8.3 \%)\end{array}$ & $46 \%$ \\
\hline
\end{tabular}

- Not available.

a Difference between estimate and 2006 estimate is statistically significant at the 0.05 level.

b Difference between estimate and 2006 estimate is statistically significant at the 0.01 level.

c Difference between estimate and previous year estimate is statistically significant at the 0.01 level.

1 Illicit drugs include marijuana/hashish, cocaine (including crack), heroin, hallucinogens, inhalants, or prescription-type psychotherapeutics used nonmedically.

2 Nonmedical use of prescription-type psychotherapeutics includes the nonmedical use of pain relievers, tranquilizers, stimulants, or sedatives, and does not

include over-the-counter drugs.

Source: SAMHSA, Office of Applied Studies, National Survey on Drug Use and Health, 1995 to 2006. 


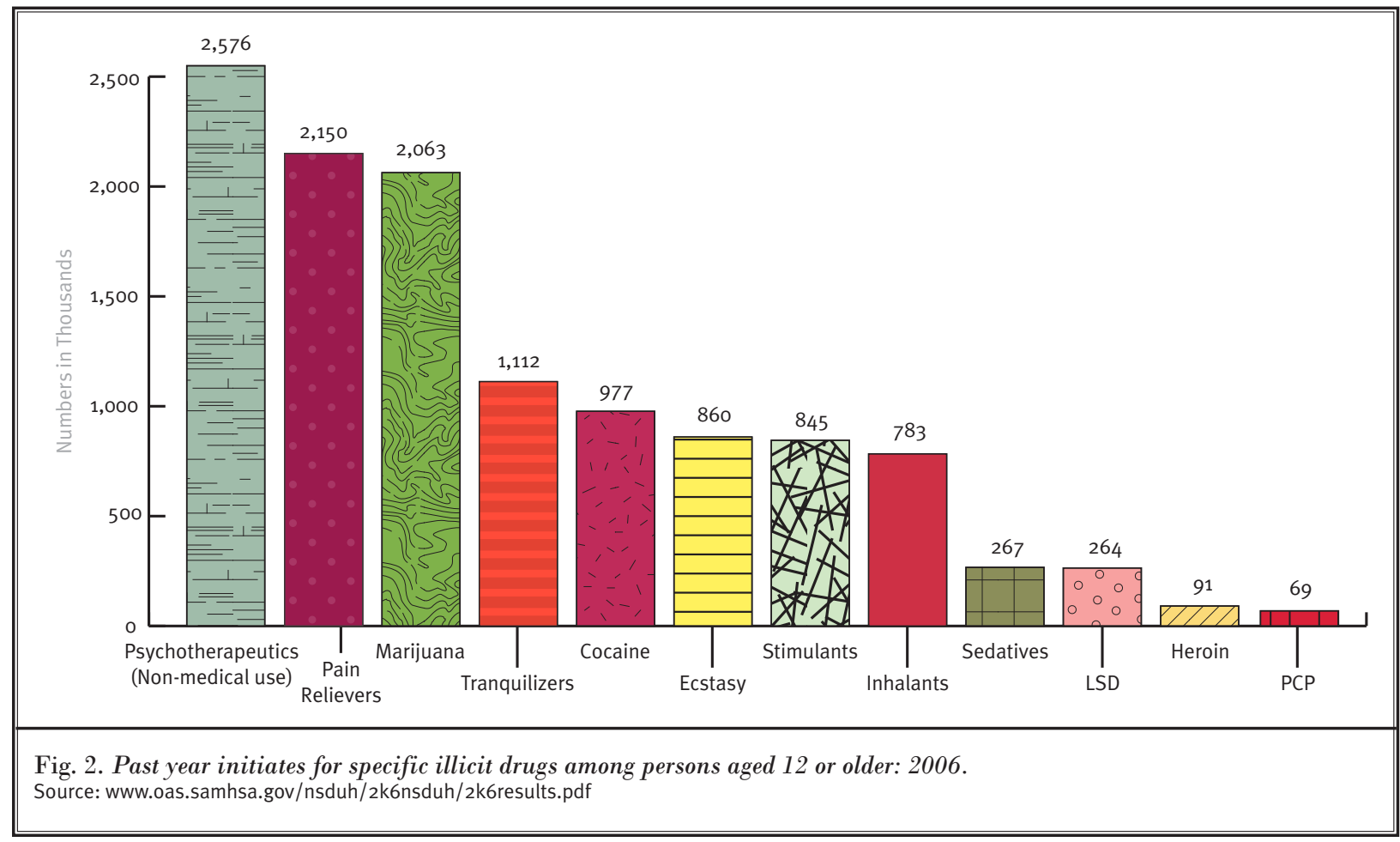

were well ahead of the illicit use of cocaine, hallucinogens, inhalants, methamphetamine, heroin, and LSD.

The increases for current (past month) nonmedical use of psychotherapeutics over a period of the last 10 years (1997 to 2006) was $162 \%$ compared to $33 \%$ for marijuana and hashish and $61 \%$ for cocaine. In fact, psychotherapeutics were the only ones that showed significant increases from 2002 to 2006, whereas, marijuana and cocaine were similar over a period of 5 years. Statistics of new initiates continue to be grim.

In 2006, there were 2.6 million persons aged 12 or older who used psychotherapeutics nonmedically for the first time within the past year (Fig. 2). Numbers of new users for specific psychotherapeutics in 2006 were 2.2 million for pain relievers, 1.1 million for tranquilizers, 845,000 for stimulants, and 267,000 for sedatives (Table 2). The specific drug categories with the largest number of recent initiatives among persons aged 12 or older were nonmedical use of pain relievers ( 2.2 million) and marijuana (2.1 million), followed by nonmedical use of tranquilizers (1.1 million), cocaine (1.0 million), ecstasy (0.9 million), stimulants (0.8 million), and inhalants (0.8 million) (Fig. 2). More strikingly, in
2006, the number of new nonmedical users of OxyContin aged 12 or older was 533,000 with an average age at first use of 22.6 years among those aged 12 to $49(1,13-16)$.

Analysis of long-term statistics based on yearly use of illicit drugs are concerning. The past year use of illicit drugs in 2006 was 35.77 million, or $14.5 \%$ of the population (Table 3). Nonmedical use of psychotherapeutics for the past year in the 2006 survey was 16.287 million compared to 15.172 million in 2005 and 14.643 million in 2004 , or $6.6 \%$ of the population aged 12 or older in $2006,6.2 \%$ in 2005 , and $6.1 \%$ in 2004 , with significant increases. Of importance is the fact that nonmedical use of psychotherapeutics was just behind marijuana and hashish with $10.3 \%$ of the population aged 12 or older in 2006 which decreased from 10.6\% in 2004 and $10.4 \%$ in 2005 (Fig. 3). However, nonmedical use of psychotherapeutics was higher than cocaine with $2.5 \%$ of the population in 2006 , compared to $2.2 \%$ for heroin, and $1.6 \%$ for hallucinogens in 2006 overall, nonmedical use of psychotherapeutics increased $167 \%$ over a period of 10 years, compared to $31 \%$ for marijuana, $46 \%$ for cocaine, and an overall increase of illicit drug use of $48 \%$. 
Therapeutic Opioid Use, Abuse, and Nonmedical Use

Table 2. Past year initiates for illicit drugs from 1997 to 2006 (numbers in thousands) for 10 years.

\begin{tabular}{|l|c|c|c|c|c|c|c|c|c|c|c||}
\hline \hline \multicolumn{1}{|c|}{ Drugs } & $\mathbf{1 9 9 7}$ & $\mathbf{1 9 9 8}$ & $\mathbf{1 9 9 9}$ & $\mathbf{2 0 0 0}$ & $\mathbf{2 0 0 1}$ & $\mathbf{2 0 0 2}$ & $\mathbf{2 0 0 3}$ & $\mathbf{2 0 0 4}$ & $\mathbf{2 0 0 5}$ & $\begin{array}{c}\text { 10-YEAR } \\
\mathbf{2 0 0 6} \text { change } \\
\text { from 1997 } \\
\text { to 2006 }\end{array}$ \\
\hline Pain Relievers & & & & & & & & & & & \\
\hline Tranquilizers & 668 & 860 & 916 & 1,298 & 1,212 & 1,184 & 1,071 & 1,180 & 1,286 & 1,112 & $66 \%$ \\
\hline Stimulants & 553 & 648 & 706 & 808 & 853 & 783 & 715 & 793 & $647^{\mathrm{a}}$ & 845 & $53 \%$ \\
\hline Sedatives & 120 & 147 & 164 & 191 & 225 & 209 & 194 & 240 & 247 & 267 & $123 \%$ \\
\hline Marijuana & 2,603 & 2,498 & 2,640 & 2,746 & 2,793 & 2,196 & 1,973 & 2,142 & 2,114 & 2,063 & $-21 \%$ \\
\hline Cocaine & 861 & 868 & 917 & 1,002 & 1,140 & 1,032 & 986 & 998 & 872 & 977 & $13 \%$ \\
\hline Heroin & 114 & 140 & 121 & 114 & 154 & 117 & 92 & 118 & 108 & 91 & $-20 \%$ \\
\hline
\end{tabular}

Note: 2002 to 2006 data is based on 2006 National Survey on Drug Use and Health Survey Report.

NOTE: Past year initiates are defined as persons who used the substance(s) for the first time in the 12 months prior to date of interview.

a Difference between estimate and 2006 estimate is statistically significant at the 0.05 level.

2 Nonmedical use of prescription-type psychotherapeutics includes the nonmedical use of pain relievers, tranquilizers, stimulants, or sedatives, and does not include over-the-counter drugs.

Source: SAMHSA, Office of Applied Studies, National Survey on Drug Use and Health, 1995 to 2006.

Table 3. Types of illicit drug use in the past year among persons aged 12 or older: numbers in thousands from 1997 to 2006 (10 years).

\begin{tabular}{|c|c|c|c|c|c|c|c|c|c|c|c|}
\hline Drugs & 1997 & 1998 & 1999 & 2000 & 2001 & 2002 & 2003 & 2004 & 2005 & 2006 & $\begin{array}{c}\text { 10-YEAR } \\
\% \text { change } \\
\text { from } 1997 \\
\text { to } 2006\end{array}$ \\
\hline $\begin{array}{l}\text { Nonmedical Use of } \\
\text { Psychotherapeutics }{ }^{2}\end{array}$ & $\begin{array}{l}6,111 \\
(2.8 \%)\end{array}$ & $\begin{array}{l}5,759 \\
(2.6 \%)\end{array}$ & $\begin{array}{l}9,220 \\
(4.2 \%)\end{array}$ & $\begin{array}{l}8,761 \\
(3.9 \%)\end{array}$ & $\begin{array}{l}11,102^{c} \\
\left(4.9 \%^{c}\right)\end{array}$ & $\begin{array}{l}14,680^{\mathrm{b}} \\
(6.2 \%)\end{array}$ & $\begin{array}{l}14,986^{\mathrm{b}} \\
(6.3 \%)\end{array}$ & $\begin{array}{l}14,643^{\mathrm{b}} \\
\left(6.1 \%^{\mathrm{b}}\right)\end{array}$ & $\begin{array}{l}15,172^{\mathrm{a}} \\
\left(6.2 \%^{\mathrm{a}}\right)\end{array}$ & $\begin{array}{l}16,287 \\
(6.6 \%)\end{array}$ & $167 \%$ \\
\hline Pain Relievers & -- & -- & $\begin{array}{l}6,582 \\
(3.0 \%)\end{array}$ & $\begin{array}{l}6,466 \\
(2.9 \%)\end{array}$ & $\begin{array}{l}8,353^{\mathrm{c}} \\
\left(3.7 \%^{\mathrm{c}}\right)\end{array}$ & $\begin{array}{l}10,992^{\mathrm{b}} \\
\left(4.7 \%^{\mathrm{b}}\right)\end{array}$ & $\begin{array}{l}11,671^{\mathrm{a}} \\
(4.9 \%)\end{array}$ & $\begin{array}{l}11,256^{\mathrm{b}} \\
\left(4.7 \%^{\mathrm{b}}\right)\end{array}$ & $\begin{array}{l}11,815^{\mathrm{a}} \\
(4.9 \%)\end{array}$ & $\begin{array}{l}12,649 \\
(5.1 \%)\end{array}$ & NA \\
\hline OxyContin ${ }^{\circ}$ & -- & -- & -- & -- & -- & -- & -- & $\begin{array}{l}1,213 \\
(0.5 \%)\end{array}$ & $\begin{array}{c}1,226 \\
(0.5 \%)\end{array}$ & $\begin{array}{c}1,323 \\
(0.5 \%)\end{array}$ & NA \\
\hline Tranquilizers & $\begin{array}{l}2,122 \\
(1.0 \%)\end{array}$ & $\begin{array}{l}1,940 \\
(0.9 \%)\end{array}$ & $\begin{array}{l}2,728 \\
(1.2 \%)\end{array}$ & $\begin{array}{c}2,731 \\
(1.2 \%)\end{array}$ & $\begin{array}{c}3,673^{c} \\
\left(1.6 \%^{c}\right)\end{array}$ & $\begin{array}{l}4,849 \\
(2.1 \%)\end{array}$ & $\begin{array}{l}5,051 \\
(2.1 \%)\end{array}$ & $\begin{array}{c}5,068 \\
(2.1 \%)\end{array}$ & $\begin{array}{c}5,249 \\
(2.2 \%)\end{array}$ & $\begin{array}{c}5,058 \\
(2.1 \%)\end{array}$ & $138 \%$ \\
\hline Stimulants & $\begin{array}{l}1,687 \\
(0.8 \%)\end{array}$ & $\begin{array}{l}1,489 \\
(0.7 \%)\end{array}$ & $\begin{array}{l}2,291 \\
(1.0 \%)\end{array}$ & $\begin{array}{l}2,112 \\
(0.9 \%)\end{array}$ & $\begin{array}{l}2,486^{c} \\
(1.1 \%) \\
\end{array}$ & $\begin{array}{l}3,181 \\
(1.4 \%)\end{array}$ & $\begin{array}{l}2,751^{\mathrm{b}} \\
\left(1.2 \%^{\mathrm{a}}\right)\end{array}$ & $\begin{array}{l}2,918^{\mathrm{a}} \\
(1.2 \%)\end{array}$ & $\begin{array}{l}2,771^{\mathrm{b}} \\
\left(1.1 \%^{\mathrm{b}}\right)\end{array}$ & $\begin{array}{c}3,394 \\
(1.4 \%) \\
\end{array}$ & $101 \%$ \\
\hline Sedatives & $\begin{array}{c}638 \\
(0.3 \%)\end{array}$ & $\begin{array}{c}522 \\
(0.2 \%)\end{array}$ & $\begin{array}{c}631 \\
(0.3 \%)\end{array}$ & $\begin{array}{c}611 \\
(0.3 \%)\end{array}$ & $\begin{array}{c}806 \\
(0.4 \%)\end{array}$ & $\begin{array}{c}981 \\
(0.4 \%)\end{array}$ & $\begin{array}{c}831 \\
(0.3 \%)\end{array}$ & $\begin{array}{c}737 \\
(0.3 \%)\end{array}$ & $\begin{array}{c}750 \\
(0.3 \%)\end{array}$ & $\begin{array}{c}926 \\
(0.4 \%)\end{array}$ & $45 \%$ \\
\hline $\begin{array}{l}\text { Marijuana and } \\
\text { Hashish }\end{array}$ & $\begin{array}{l}19,446 \\
(9.0 \%)\end{array}$ & $\begin{array}{l}18,710 \\
(8.6 \%)\end{array}$ & $\begin{array}{l}19,102 \\
(8.6 \%)\end{array}$ & $\begin{array}{l}18,589 \\
(8.3 \%)\end{array}$ & $\begin{array}{l}21,086^{c} \\
\left(9.3 \%^{c}\right)\end{array}$ & $\begin{array}{c}25,755 \\
\left(11.0 \%{ }^{\mathrm{a}}\right) \\
\end{array}$ & $\begin{array}{c}25,231 \\
(10.6 \%) \\
\end{array}$ & $\begin{array}{c}25,451 \\
(10.6 \%)\end{array}$ & $\begin{array}{r}25,375 \\
(10.4 \%) \\
\end{array}$ & $\begin{array}{c}25,378 \\
(10.3 \%)\end{array}$ & $31 \%$ \\
\hline Cocaine & $\begin{array}{c}4,169 \\
(1.9 \%)\end{array}$ & $\begin{array}{c}3,811 \\
(1.7 \%)\end{array}$ & $\begin{array}{c}3,742 \\
(1.7 \%)\end{array}$ & $\begin{array}{c}3,328 \\
(1.5 \%)\end{array}$ & $\begin{array}{l}4,186^{c} \\
\left(1.9 \%^{c}\right)\end{array}$ & $\begin{array}{l}5,902 \\
(2.5 \%)\end{array}$ & $\begin{array}{l}5,908 \\
(2.5 \%)\end{array}$ & $\begin{array}{l}5,658 \\
(2.4 \%)\end{array}$ & $\begin{array}{l}5,523 \\
(2.3 \%) \\
\end{array}$ & $\begin{array}{l}6,069 \\
(2.5 \%) \\
\end{array}$ & $46 \%$ \\
\hline $\begin{array}{l}\text { TOTAL } \\
\text { ILLICIT DRUGS }\end{array}$ & $\begin{array}{c}24,189 \\
(11.2 \%)\end{array}$ & $\begin{array}{c}23,115 \\
(10.6 \%)\end{array}$ & $\begin{array}{l}25,402 \\
(11.5 \%)\end{array}$ & $\begin{array}{c}24,535 \\
(11.0 \%)\end{array}$ & $\begin{array}{l}28,409^{c} \\
\left(12.6 \%^{c}\right)\end{array}$ & $\begin{array}{c}35,132 \\
(14.9 \%)\end{array}$ & $\begin{array}{c}34,993 \\
(14.7 \%)\end{array}$ & $\begin{array}{c}34,807 \\
(14.5 \%)\end{array}$ & $\begin{array}{c}35,041 \\
(14.4 \%)\end{array}$ & $\begin{array}{c}35,775 \\
(14.5 \%)\end{array}$ & $48 \%$ \\
\hline
\end{tabular}

Note: 2002 to 2006 data is based on 2006 National Survey on Drug Use and Health Survey Report.

Figures in () indicate percentage.

-- Not available.

a Difference between estimate and 2006 estimate is statistically significant at the 0.05 level.

b Difference between estimate and 2006 estimate is statistically significant at the 0.01 level.

c Estimate is statistically different than previous year

1 Illicit drugs include marijuana/hashish, cocaine (including crack), heroin, hallucinogens, inhalants, or prescription-type psychotherapeutics used

nonmedically.

2 Nonmedical use of prescription-type psychotherapeutics includes the nonmedical use of pain relievers, tranquilizers, stimulants, or sedatives, and does not include over-the-counter drugs.

Source: SAMHSA, Office of Applied Studies, National Survey on Drug Use and Health, 1995 to 2006. 


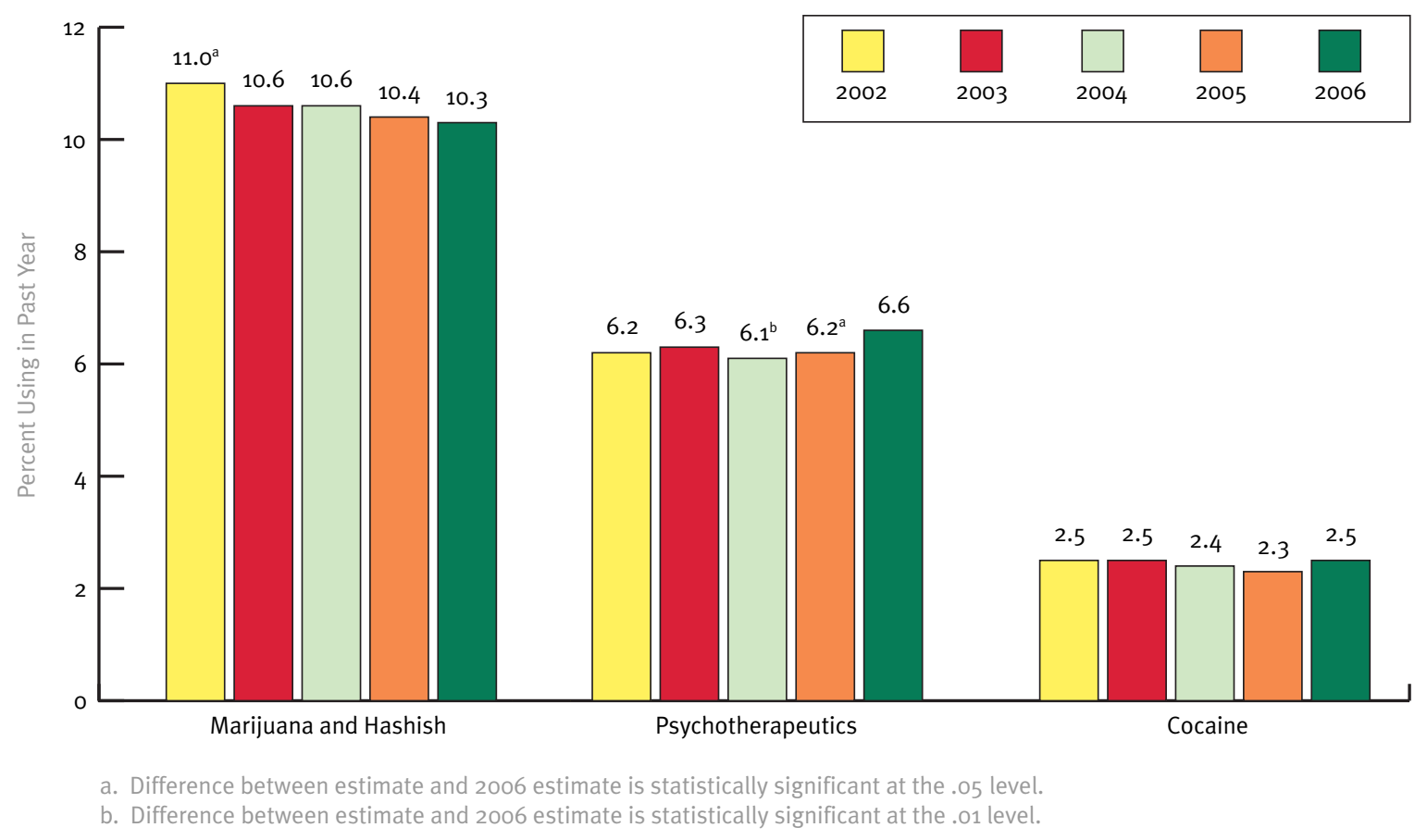

Fig. 3. Past year use of selected illicit drugs among persons aged 12 or older: 2002 - 2006 (12).

Source: www.oas.samhsa.gov/nsduh/2k6nsduh/2k6results.pdf

Not surprisingly, lifetime use of illicit drugs (lifetime use indicates use of a specific drug at least once in the respondent's lifetime), including psychotherapeutics, among persons aged 12 or older has been increasing over the years (Table 4, Fig. 4). However, in 2006 the lifetime use of illicit drugs among persons aged 12 or older was slightly less than 2005 with 111,774 or $45.4 \%$ of the population, a decrease from $46.1 \%$ of the population in 2005 . In contrast, nonmedical use of psychotherapeutics increased from $20 \%$ of the population in 2005 to $20.3 \%$ in 2006 , or almost 50 million using prescription psychotherapeutic drugs for nonmedical purposes. Among the subgroups, only OxyContin increased significantly from 2004 to 2005 to 3,481 , and to 4,098 in 2006 , or $1.4 \%$ of the population in 2005 to $1.7 \%$ in 2006 . Lifetime use of illicit drugs in persons aged 12 or older was topped by marijuana (39.8\% of the population) followed by nonmedical use of psychotherapeutics (20.3\% of the population). However, nonmedical use of psychotherapeutics was $153 \%$ higher than the lifetime use of cocaine $(56 \%)$ or marijuana (38\%), over a period of 10 years from 1997 to 2006.

\section{Abuse Based on Age}

Rates of past month illicit drug use varied with age. Through the adolescent years from 12 to 17 , the rates of current illicit drug use in 2006 increased from $3.9 \%$ at ages 12 or 13 , to $9.1 \%$ at ages 14 or 15 , to $16 \%$ at ages 16 or 17 . However, the highest rate of $22.2 \%$ was noted among persons aged 18 to 20 (Fig. 5) (1). Even though the statistics show that adults aged 26 or older were less likely to be current drug users than their younger counterparts, overall there were more drug users aged 26 or older ( 11.4 million) than in the 12 to 17 year age group ( 2.5 million) and the 18 to 25 year age group (6.5 million) combined. In 2006, $9.8 \%$ of youths aged 12 to 17 were current illicit drug users: $6.7 \%$ used marijuana, $3.3 \%$ used prescription drugs nonmedically, $1.3 \%$ used inhalants, $0.7 \%$ used hallucinogens, and $0.4 \%$ used cocaine (1).

In 2006, young adults aged 18 to 25 demonstrated rates of current use of illicit drugs to be higher $(19.8 \%)$ than for youths aged 12 to 17 and adults aged 26 or older, with $16.3 \%$ using marijuana, $6.4 \%$ using psychotherapeutics nonmedically, $2.2 \%$ using cocaine, and 


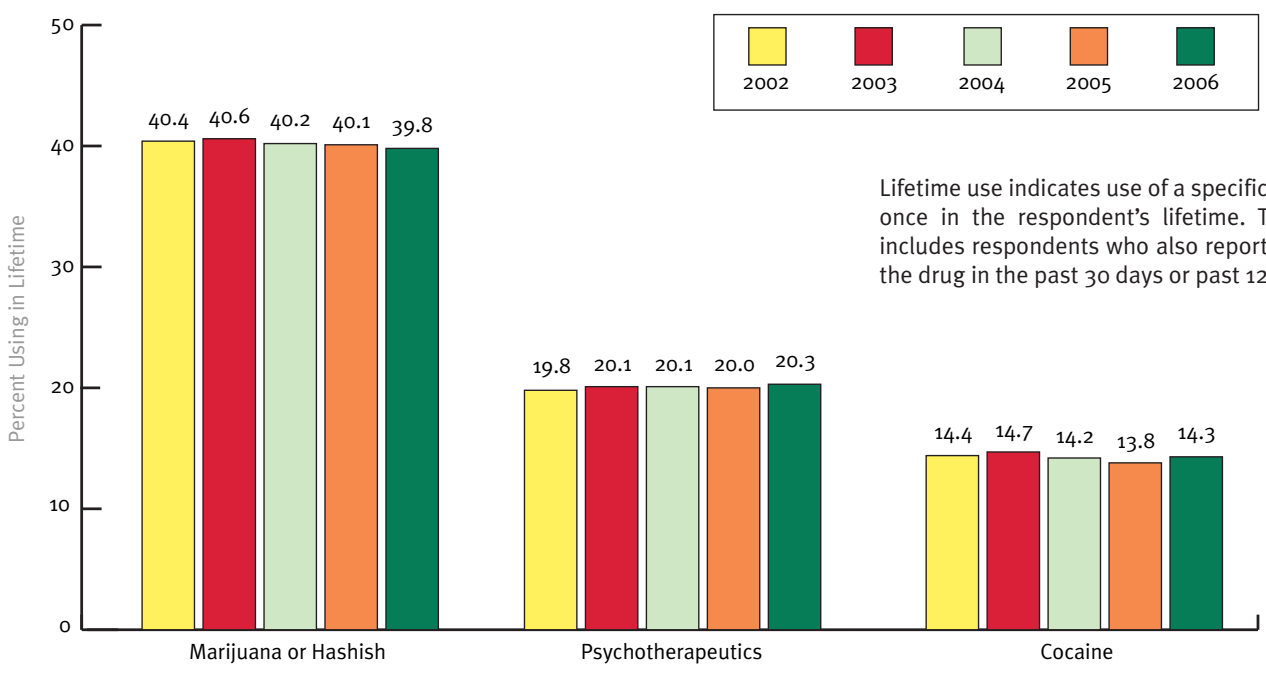

Fig. 4. Lifetime use of selected illicit drugs.

Source: www.oas.samhsa.gov/nsduh/2k6nsduh/2k6results.pdf

Table 4. Types of illicit drugs of lifetime use among persons aged 12 or older: numbers in thousands, 1997 - 2006.

\begin{tabular}{|c|c|c|c|c|c|c|c|c|c|c|c|}
\hline Drug & 1997 & 1998 & 1999 & 2000 & 2001 & 2002 & 2003 & 2004 & 2005 & 2006 & $\begin{array}{c}\% \\
\text { change } \\
\text { from } \\
1997 \\
\text { to } 2006\end{array}$ \\
\hline $\begin{array}{l}\text { Nonmedical } \\
\text { Use of } \\
\text { Psychotherapeutics }{ }^{2}\end{array}$ & $\begin{array}{l}19,671 \\
(9.1 \%)\end{array}$ & $\begin{array}{l}20,193 \\
(9.2 \%)\end{array}$ & $\begin{array}{c}34,076 \\
(15.4 \%)\end{array}$ & $\begin{array}{c}32,443 \\
\left(14.5 \%^{c}\right)\end{array}$ & $\begin{array}{l}36,028^{c} \\
\left(16.0 \%^{c}\right)\end{array}$ & $\begin{array}{l}46,558^{\mathrm{b}} \\
(19.8 \%)\end{array}$ & $\begin{array}{l}47,882^{\mathrm{a}} \\
(20.1 \%)\end{array}$ & $\begin{array}{c}48,013 \\
(20.0 \%)\end{array}$ & $\begin{array}{c}48,709 \\
(20.0 \%)\end{array}$ & $\begin{array}{c}49,842 \\
(20.3 \%)\end{array}$ & $153 \%$ \\
\hline Pain Relievers & -- & -- & $\begin{array}{l}19,888 \\
(9.0 \%) \\
\end{array}$ & $\begin{array}{l}19,210 \\
(8.6 \%)\end{array}$ & $\begin{array}{l}22,133^{c} \\
\left(9.8 \%^{c}\right)\end{array}$ & $\begin{array}{r}29,611^{\mathrm{b}} \\
\left(12.6 \%^{\mathrm{b}}\right) \\
\end{array}$ & $\begin{array}{l}31,207^{\mathrm{b}} \\
(13.1 \%)\end{array}$ & $\begin{array}{l}31,768^{\mathrm{a}} \\
(13.2 \%)\end{array}$ & $\begin{array}{c}32,692 \\
(13.4 \%) \\
\end{array}$ & $\begin{array}{c}33,472 \\
(13.6 \%)\end{array}$ & NA \\
\hline OxyContin $^{\circ}$ & -- & -- & -- & -- & -- & $\begin{array}{l}1,924^{\mathrm{b}} \\
\left(0.8 \%^{\mathrm{b}}\right)\end{array}$ & $\begin{array}{l}2,832^{\mathrm{b}} \\
\left(1.2 \%^{\mathrm{b}}\right)\end{array}$ & $\begin{array}{l}3,072^{\mathrm{b}} \\
\left(1.3 \%^{\mathrm{b}}\right)\end{array}$ & $\begin{array}{l}3,481^{\mathrm{b}} \\
(1.4 \%)^{\mathrm{b}}\end{array}$ & $\begin{array}{c}4,098 \\
(1.7 \%)\end{array}$ & NA \\
\hline Tranquilizers & $\begin{array}{c}6,931 \\
(3.2 \%) \\
\end{array}$ & $\begin{array}{c}7,726 \\
(3.5 \%) \\
\end{array}$ & $\begin{array}{l}13,860 \\
(6.3 \%) \\
\end{array}$ & $\begin{array}{l}13,007 \\
(5.8 \%) \\
\end{array}$ & $\begin{array}{l}13,945 \\
(6.2 \%) \\
\end{array}$ & $\begin{array}{l}19,267^{\mathrm{b}} \\
(8.2 \%)\end{array}$ & $\begin{array}{l}20,220 \\
(8.5 \%) \\
\end{array}$ & $\begin{array}{r}19,852^{\mathrm{a}} \\
(8.3 \%)\end{array}$ & $\begin{array}{l}21,041 \\
(8.7 \%) \\
\end{array}$ & $\begin{array}{l}21,303 \\
(8.7 \%) \\
\end{array}$ & $207 \%$ \\
\hline Stimulants & $\begin{array}{c}9,781 \\
(4.5 \%)\end{array}$ & $\begin{array}{l}9,614 \\
(4.4 \%)\end{array}$ & $\begin{array}{l}15,922 \\
(7.2 \%)\end{array}$ & $\begin{array}{l}14,661^{c} \\
\left(6.6 \%{ }^{c}\right)\end{array}$ & $\begin{array}{l}16,007^{c} \\
\left(7.1 \%^{c}\right)\end{array}$ & $\begin{array}{l}21,072 \\
\left(9.0 \%^{\mathrm{b}}\right)\end{array}$ & $\begin{array}{l}20,798 \\
\left(8.8 \%^{\mathrm{a}}\right)\end{array}$ & $\begin{array}{l}19,982 \\
(8.3 \%)\end{array}$ & $\begin{array}{l}19,080 \\
(7.8 \%)\end{array}$ & $\begin{array}{l}20,118 \\
(8.2 \%)\end{array}$ & $106 \%$ \\
\hline Sedatives & $\begin{array}{c}4,080 \\
(1.9 \%)\end{array}$ & $\begin{array}{c}4,640 \\
(2.1 \%)\end{array}$ & $\begin{array}{c}7,747 \\
(3.5 \%)\end{array}$ & $\begin{array}{c}7,142 \\
(3.2 \%)\end{array}$ & $\begin{array}{c}7,477 \\
(3.3 \%)\end{array}$ & $\begin{array}{l}9,960^{\mathrm{a}} \\
\left(4.2 \%^{\mathrm{b}}\right) \\
\end{array}$ & $\begin{array}{c}9,510 \\
\left(4.0 \%^{\mathrm{a}}\right)\end{array}$ & $\begin{array}{r}9,891^{\mathrm{a}} \\
\left(4.1 \%^{\mathrm{a}}\right)\end{array}$ & $\begin{array}{c}8,982 \\
(3.7 \%)\end{array}$ & $\begin{array}{c}8,822 \\
(3.6 \%)\end{array}$ & $116 \%$ \\
\hline $\begin{array}{l}\text { Marijuana and } \\
\text { Hashish }\end{array}$ & $\begin{array}{c}71,112 \\
(32.9 \%)\end{array}$ & $\begin{array}{l}72,070 \\
(33.0 \%)\end{array}$ & $\begin{array}{l}76,428 \\
(34.6 \%)\end{array}$ & $\begin{array}{c}76,321 \\
(34.2 \%)\end{array}$ & $\begin{array}{c}83,272^{c} \\
\left(36.9 \%^{c}\right)\end{array}$ & $\begin{array}{l}94,946^{\mathrm{a}} \\
(40.4 \%)\end{array}$ & $\begin{array}{c}96,611 \\
(40.6 \%)\end{array}$ & $\begin{array}{c}96,772 \\
(40.2 \%)\end{array}$ & $\begin{array}{l}97,545 \\
(40.1 \%)\end{array}$ & $\begin{array}{c}97,825 \\
(39.8 \%)\end{array}$ & $38 \%$ \\
\hline Cocaine & $\begin{array}{c}22,597 \\
(10.5 \%)\end{array}$ & $\begin{array}{c}23,089 \\
(10.6 \%)\end{array}$ & $\begin{array}{c}25,406 \\
(11.5 \%)\end{array}$ & $\begin{array}{c}24,896 \\
(11.2 \%)\end{array}$ & $\begin{array}{c}27,788^{\mathrm{c}} \\
\left(12.3 \%^{\mathrm{c}}\right)\end{array}$ & $\begin{array}{c}33,910 \\
(14.4 \%)\end{array}$ & $\begin{array}{c}34,891 \\
(14.7 \%)\end{array}$ & $\begin{array}{c}34,153 \\
(14.2 \%)\end{array}$ & $\begin{array}{c}33,673 \\
(13.8 \%)\end{array}$ & $\begin{array}{c}35,298 \\
(14.3 \%)\end{array}$ & $56 \%$ \\
\hline $\begin{array}{l}\text { TOTAL } \\
\text { ILLICIT } \\
\text { DRUGS }^{1}\end{array}$ & $\begin{array}{l}76,960 \\
(35.6 \%)\end{array}$ & $\begin{array}{l}78,123 \\
(35.8 \%)\end{array}$ & $\begin{array}{c}87,734 \\
(39.7 \%)\end{array}$ & $\begin{array}{l}86,931 \\
(38.9 \%)\end{array}$ & $\begin{array}{c}94,140^{c} \\
\left(41.7 \%^{c}\right)\end{array}$ & $\begin{array}{l}108,255^{b} \\
(46.0 \%)\end{array}$ & $\begin{array}{l}110,205 \\
(46.4 \%)\end{array}$ & $\begin{array}{l}110,057 \\
(45.8 \%)\end{array}$ & $\begin{array}{l}112,085 \\
(46.1 \%)\end{array}$ & $\begin{array}{l}111,774 \\
(45.4 \%)\end{array}$ & $45 \%$ \\
\hline
\end{tabular}

-- Not available.

a Difference between estimate and 2006 estimate is statistically significant at the 0.05 level.

b Difference between estimate and 2006 estimate is statistically significant at the 0.01 level.

c Difference between estimate and previous year estimate is statistically significant at the 0.01 level.

1 Illicit drugs include marijuana/hashish, cocaine (including crack), heroin, hallucinogens, inhalants, or prescription-type psychotherapeutics used nonmedically.

2 Nonmedical use of prescription-type psychotherapeutics includes the nonmedical use of pain relievers, tranquilizers, stimulants, or sedatives, and does not include over-the-counter drugs.

Source: SAMHSA, Office of Applied Studies, National Survey on Drug Use and Health, 1995 to 2006. 


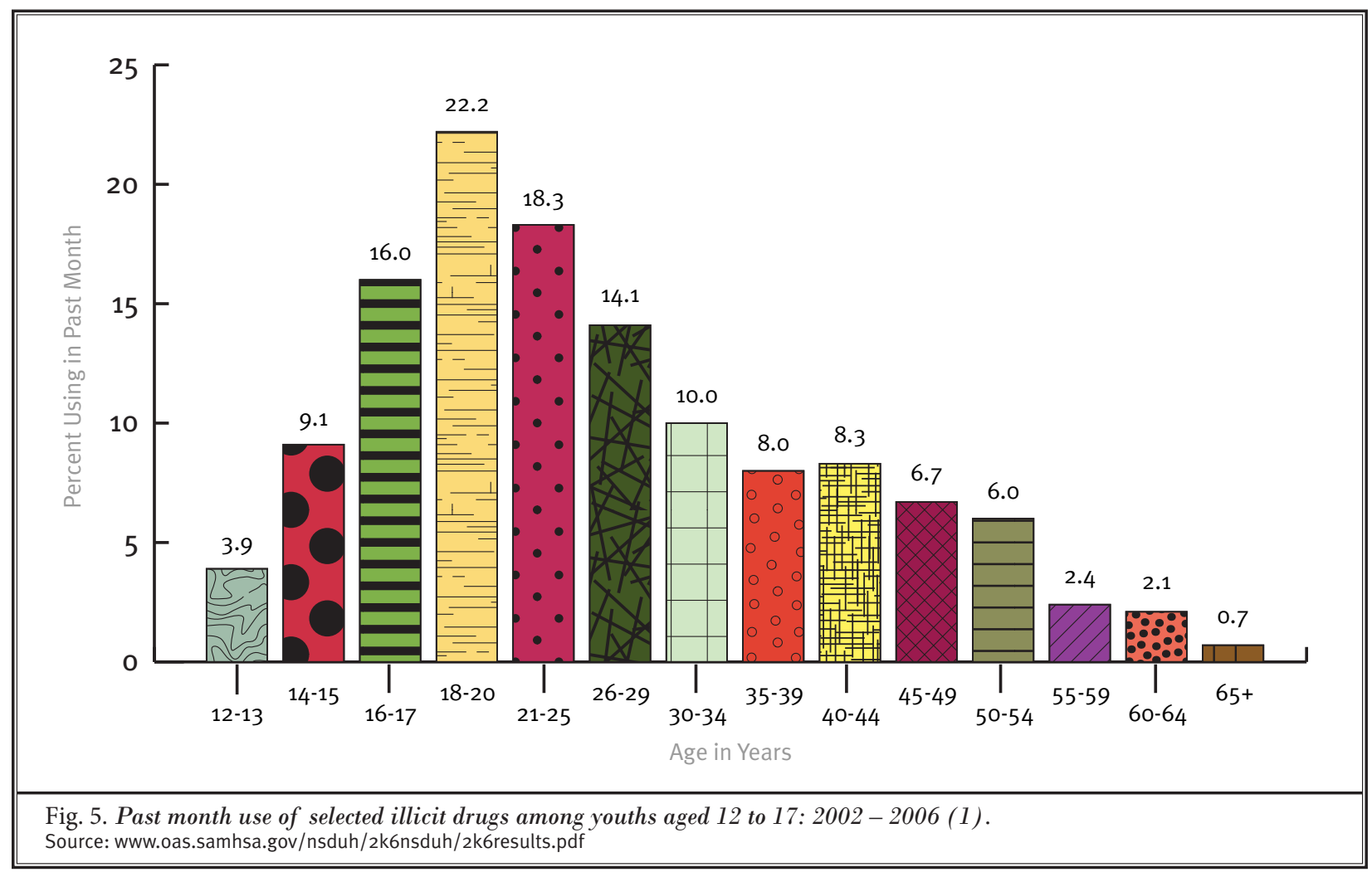

$1.7 \%$ using hallucinogens (Fig. 6). Past month nonmedical use of prescription-type drugs among young adults increased from $5.4 \%$ in 2002 to $6.4 \%$ in 2006 . This was primarily due to an increase in the rate of pain reliever use which was $4.1 \%$ in 2002 and $4.9 \%$ in 2006. Further, during the same period the nonmedical use of tranquilizers also increased from $1.6 \%$ to $2 \%$.

Lifetime, past year, and current nonmedical use of psychotherapeutic drugs among young adults aged 18 to 25 also increased between 2002 and 2006, 27.7\% vs. $30.3 \%$ for lifetime use, $14.2 \%$ vs. $15.5 \%$ for past year use, and $1.9 \%$ vs. $2.1 \%$ for current use, with increases in the rates of pain relievers and tranquilizer use (1).

\section{Gender}

In 2006, the survey results were similar to prior years with males being more likely than females to be current illicit drug users (10.5\% vs. $6.2 \%)$. However, the rate of past month marijuana use for males was about twice as high as the rate for females. The rate of past month nonmedical use of psychotherapeutic drugs increased from $2.8 \%$ to $3.2 \%$ among males, whereas there were no significant changes in the rate of past month drug use among females aged 12 or older (1).

\section{Pregnancy}

Among pregnant woman aged 15 to 44 years, a significantly lower proportion of women used illicit drugs $(4 \%)$ compared to their nonpregnant counterparts of $10 \%(1)$.

\section{Employment}

Employment also seems to have a significant influence. Among adults aged 18 or older, the current rate of illicit drug use was higher for unemployed persons $(18.5 \%)$ than for those who were employed full-time $(8.8 \%)$ or part-time $(9.4 \%)$, the results being similar and comparable to 2005. Of approximately 18 million current illicit drug users aged 18 or older in 2006 , nearly $75 \%$, or over 13 million, were employed either full-or part-time (1).

\section{Region}

There were also differences based on geographic area among persons aged 12 or older. The rate of current illicit drug use in 2006 was $9.5 \%$ in the West, $8.9 \%$ in the Northeast, $7.9 \%$ in the Midwest, and $7.4 \%$ in the South $(12,88)$. Further, the rate of current illicit drug use in metropolitan areas was higher than the rate in 


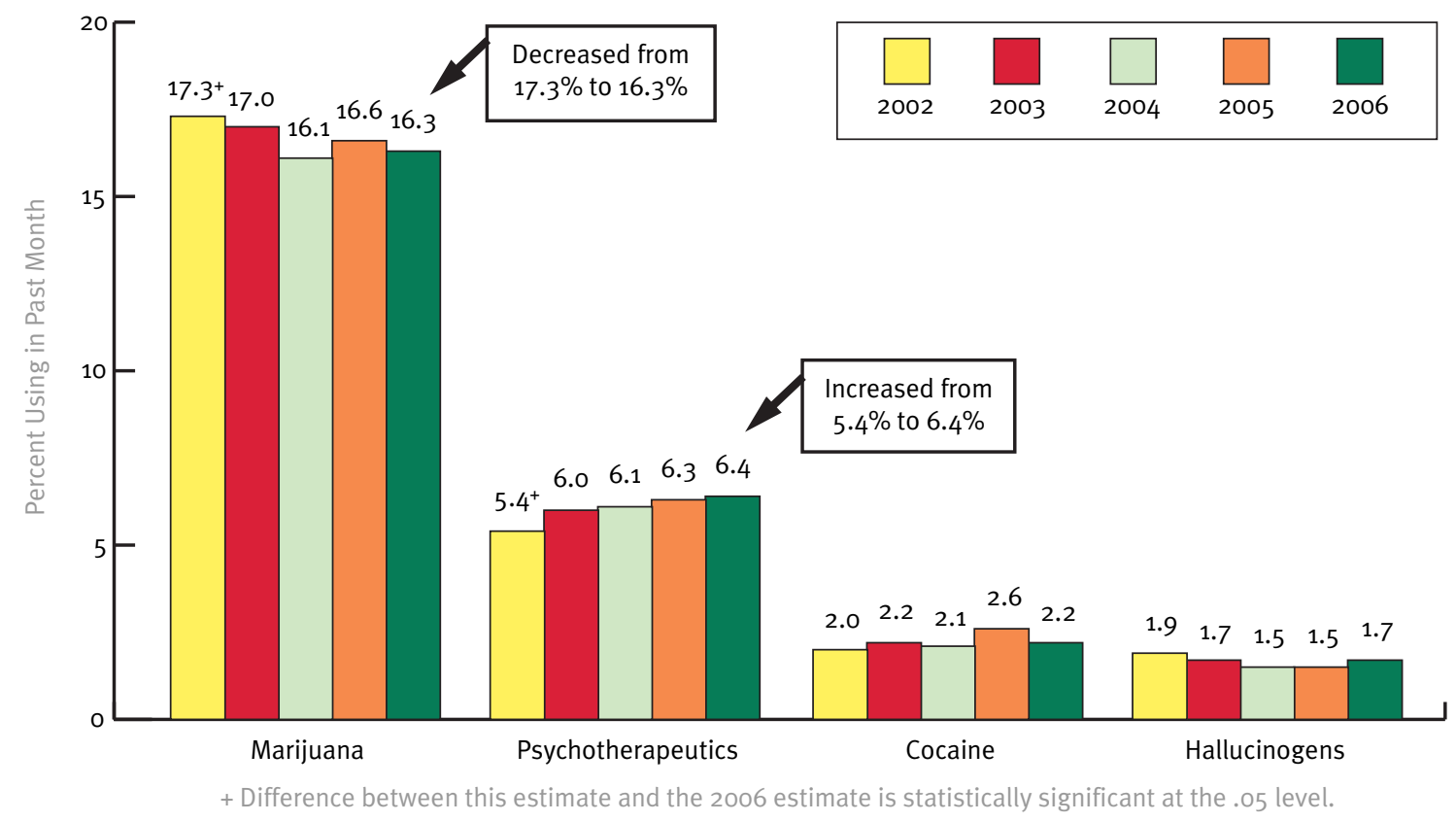

Fig. 6. Past month use of selected illicit drugs among young adults aged 18 to 25: 2002 - 2006. Source: www.oas.samhsa.gov/nsduh/2k6nsduh/2k6results.pdf

nonmetropolitan areas with $8.7 \%$ in large metropolitan counties, $8.3 \%$ in small metropolitan counties, and $6.8 \%$ in nonmetropolitan counties as a group (1).

\section{Mental Health Problems}

The NSDUH survey of 2006 evaluated the prevalence and treatment of serious psychological distress (SPD) and major depressive episode (MDE) and the association of these problems with substance use and substance dependency or abuse. SPD is an overall indicator of the past year of psychological distress, whereas MDE is defined as a period of at least 2 weeks when a person experienced a depressed mood or loss of interest or pleasure in daily activities and had symptoms that met the criteria for a major depressive disorder (1).

\section{Adults Aged 18 or Older}

The prevalence of serious psychological distress in 2006 was shown in 24.9 million adults, representing $11.3 \%$ of all adults, with the highest rates being in adults aged 18 to $25(17.7 \%)$ and lowest for adults aged 50 or older $(6.9 \%)$ as shown in Fig. 7A (1). The prevalence of SPD among women aged 18 or older was higher $(13.7 \%)$ than among men $(8.7 \%)$ in that age group (1).

Past year illicit drug use was higher among adults aged 18 or older with SPD $(27.2 \%)$ than among adults without SPD (12.3\%). Overall there were 5.6 million adults (Fig. 7B) aged 18 or older with both SPD and substance dependence or abuse disorder in 2006, with only half $(50.8 \%)$ receiving mental health treatment or substance abuse treatment at a specialty facility (1).

The prevalence of a major depressive episode in 2006 was $7.2 \%$ of persons aged 18 or older, or 15.8 million adults, with at least 1 major depressive episode in the past year. In 2006, an estimated 30.4 million persons aged 18 or older had had at least 1 MDE in their lifetime (13.9\%) as illustrated in Fig. 8B (1). The rate was $15 \%$ among persons aged 18 to $25,15.9 \%$ among persons aged 26 to 49 , and $11.1 \%$ among persons aged 50 or older (1). In addition, the past year prevalence of MDE in 2006 was lowest for those aged 50 or older, whereas it was higher among adult females (Fig. 8B).

In 2006, an adult aged 18 or older with a combination of a major depressive episode and substance use and dependence or abuse in the past year was more likely than those with MDE to have used an illicit drug in the past year $(27.7 \%$ vs $12.9 \%)$ (1). A similar pattern 


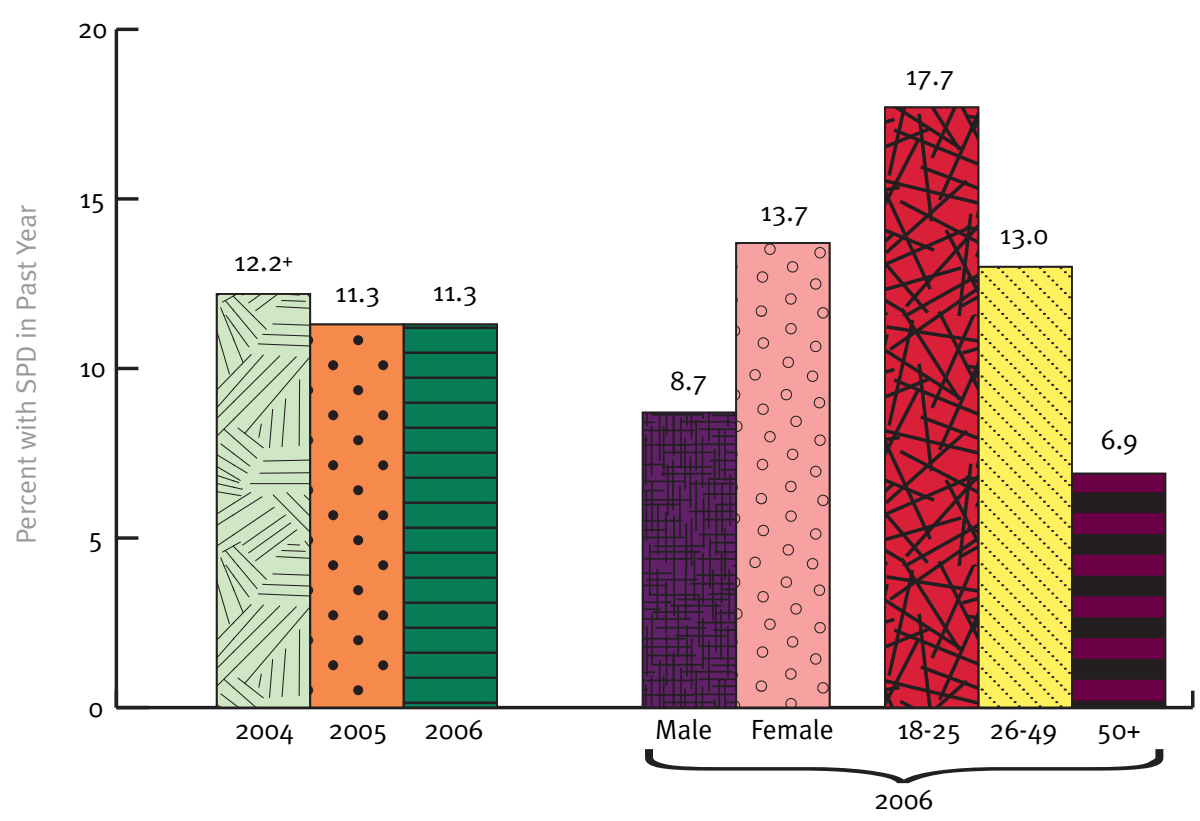

+ Difference between this estimate and the 2006 estimate is statistically significant at the .05 level.

A. Serious psychological distress (SPD) in the past year among adults aged 18 or older, by year, gender, and age: 2004 - 2006 (1).

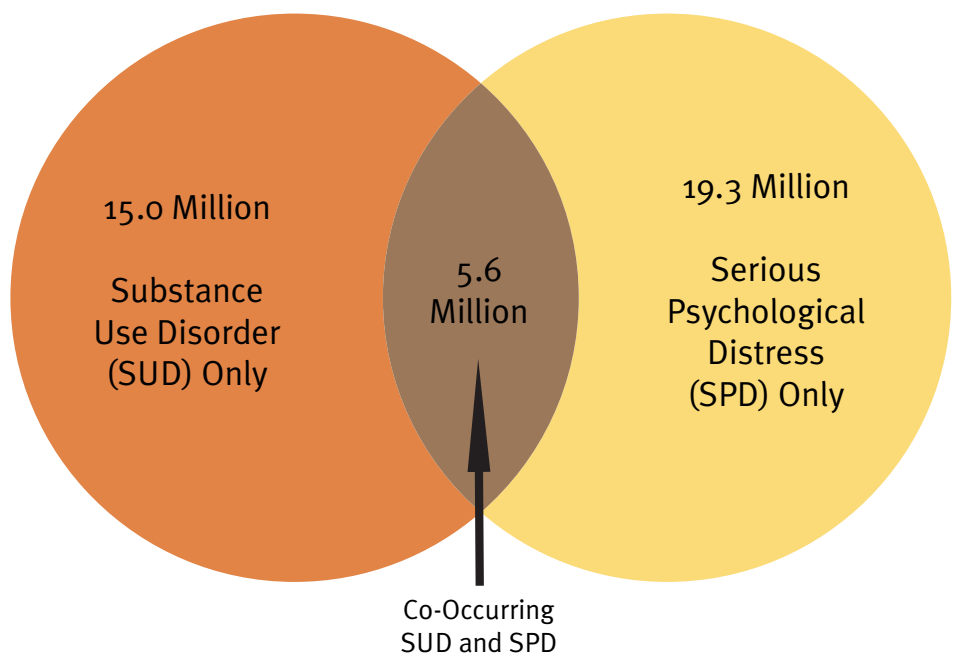

B. Co-occurrence of serious psychological distress and substance use disorder in the past year among adults aged 18 or older: 2006 (1).

Fig. 7. Serious psychological distress and substance abuse disorders.

Source: www.oas.samhsa.gov/nsduh/2k6nsduh/2k6results.pdf 


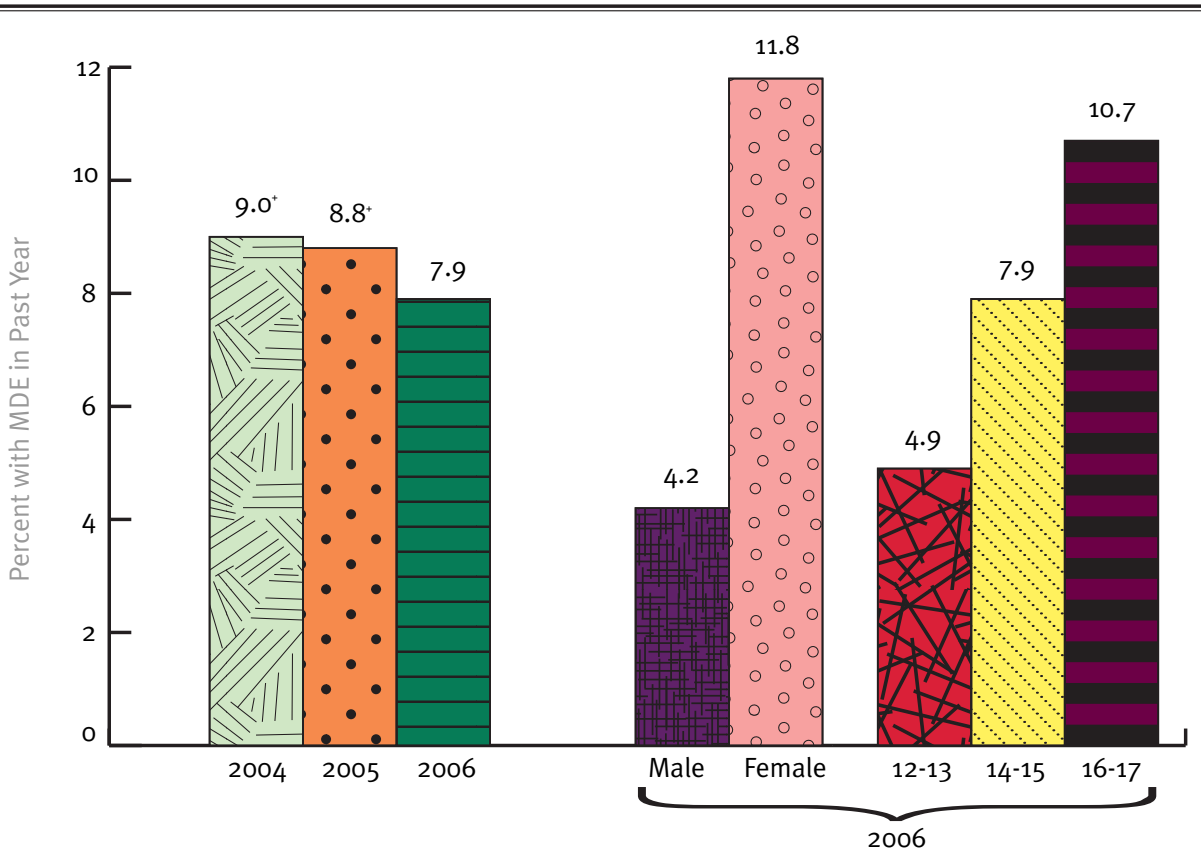

+ Difference between this estimate and the 2006 estimate is statistically significant at the .05 level.

A. Major depressive episode in the past year among youths aged 12 to 17 , by year, gender, and age: $2004-2006$.

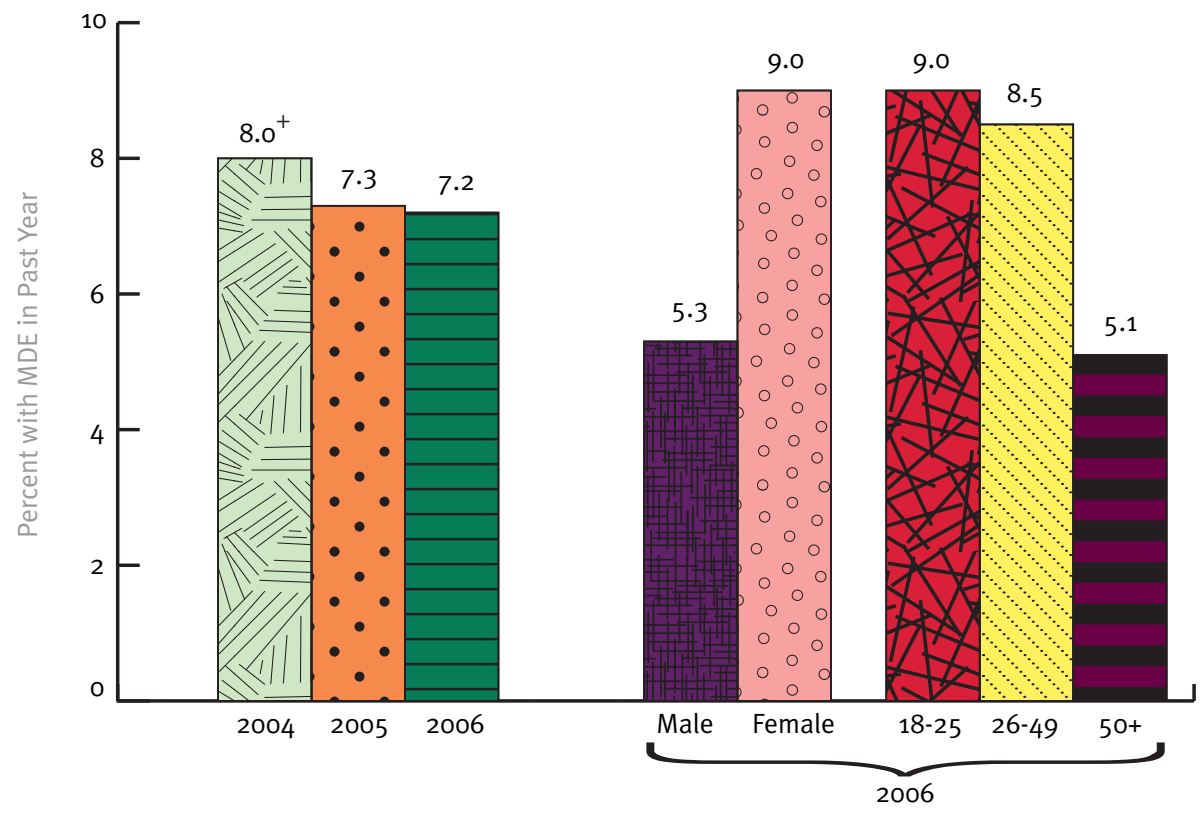

+ Difference between this estimate and the 2006 estimate is statistically significant at the .05 level.

B. Major depressive episode in the past year among youths aged 18 or older, by year, gender, and age: $2004-2006$.

Fig. 8. Prevalence of major depressive episode (MDE) (1).

Source: www.oas.samhsa.gov/nsduh/2k6nsduh/2k6results.pdf 
was observed for specific types of past year illicit drug use, such as marijuana and the nonmedical use of prescription-type psychotherapeutics. Thus, having MDE in the past year was associated with higher past year substance dependence or abuse among adults aged 18 or older, with approximately $24 \%$ being dependent on or having abused alcohol or illicit drugs, while among adults without MDE only $8.1 \%$ were dependent on or had abused alcohol or illicit drugs (1).

\section{Youths Aged 12 to 17}

The prevalence of a major depressive episode in youths aged 12 to 17 in 2006 showed that 3.2 million $(12.8 \%)$ reported at least $1 \mathrm{MDE}$ in their lifetime and 2.0 million youths $(7.9 \%)$ had an MDE during the past year. Among the youths aged 12 to 17 , the past year prevalence of MDE ranged from $4 \%$ among 12 year olds to $11.1 \%$ among those aged 16 and $10.3 \%$ among those aged 17 (Fig. 8A) (1).

Among youths aged 12 to 17 with MDE, $34.6 \%$ had used illicit drugs during the same period. This was higher than the $18.2 \%$ of youths who did not have a past year MDE who had used illicit drugs during the past year. This pattern, however, was similar to specific types of illicit drug use including marijuana and the nonmedical use of prescription-type psychotherapeutics (1).

\section{Other Factors}

Other factors described included criminal justice populations. In 2006, there were an estimated 1.6 million adults aged 18 or older on parole or other supervised release from prison during the past year, with $29.7 \%$ using illicit drugs, higher than the $7.9 \%$ of adults not on parole or supervised release. Further, the statistics are also grim in populations on probation with $31.9 \%$, of 4.6 million adults, on probation at some time in the past year using illicit drugs, which is higher than the rate of $7.6 \%$ among adults not on probation in 2006 (1).

\section{Frequency of Abuse}

Among past year marijuana users aged 12 or older in 2006, the following patterns were revealed (1):

- $12.3 \%$ used marijuana on 300 or more days within the past 12 months, translating to 3.1 million using marijuana on a daily or almost daily basis over a 12-month period. The results were similar to the estimate in 2005.

- $34.4 \%$, or 5.1 million, used the drug on 20 or more days in the past month (current use).

\section{Driving}

Driving under the influence of illicit drugs is criminal and dangerous to the public. In 2006, 10.2 million persons, or $4.2 \%$ of the population aged 12 or older, reported driving under the influence of illicit drugs during the past year. This rate was highest among young adults aged 18 to 25 with $13 \%$ (1).

\section{Source of Prescription Drugs}

Of importance to the medical profession is the source of prescription-type pain relievers used nonmedically. Among persons aged 12 or older who used pain relievers nonmedically in the past 12 months, $55.7 \%$ reported that the source of the drug was a friend or relative for free (1). An additional $19.1 \%$ reported that they got the drug from just 1 doctor. In contrast, only $3.9 \%$ got the pain relievers from a drug dealer or other stranger, and only $0.1 \%$ reported buying the drug on the internet (Fig. 9).

In $80.7 \%$ of the cases where nonmedical users of prescription pain relievers obtained their drugs from a friend or relative for free, the individuals indicated that their friend or relative had obtained the drugs from just 1 doctor (1). Only $1.6 \%$ reported that a friend or relative had bought the drug from a drug dealer or other stranger (Fig. 9). Even further striking is the fact that in 2006 , over half $(53.6 \%)$ of past year methamphetamine users reported that they obtained the methamphetamine they used most recently from a friend or relative for free, with an additional $21.4 \%$ buying it from a friend or relative. Only 1 in 5 users of methamphetamine $(21.1 \%)$ bought it from a drug dealer or other stranger (1).

\section{Attitudes on Substance Abuse}

In a survey conducted by the National Center of Addiction and Substance Abuse at Columbia University (89), it was concluded that since 2002 the proportion of students who attend schools where drugs are used, kept, or sold has jumped 39\% for high school students and $63 \%$ for middle school students. The CASA in-depth survey of drugs in schools shows that 8 out of 10 high school students $(80 \%)$ and more than 4 out of 10 middle school students (44\%) have personally witnessed:

- Illegal drugs used on the grounds of their schools.

- Illegal drugs sold on the grounds of their schools.

- Students keeping illegal drugs at school either on them or in their lockers. 


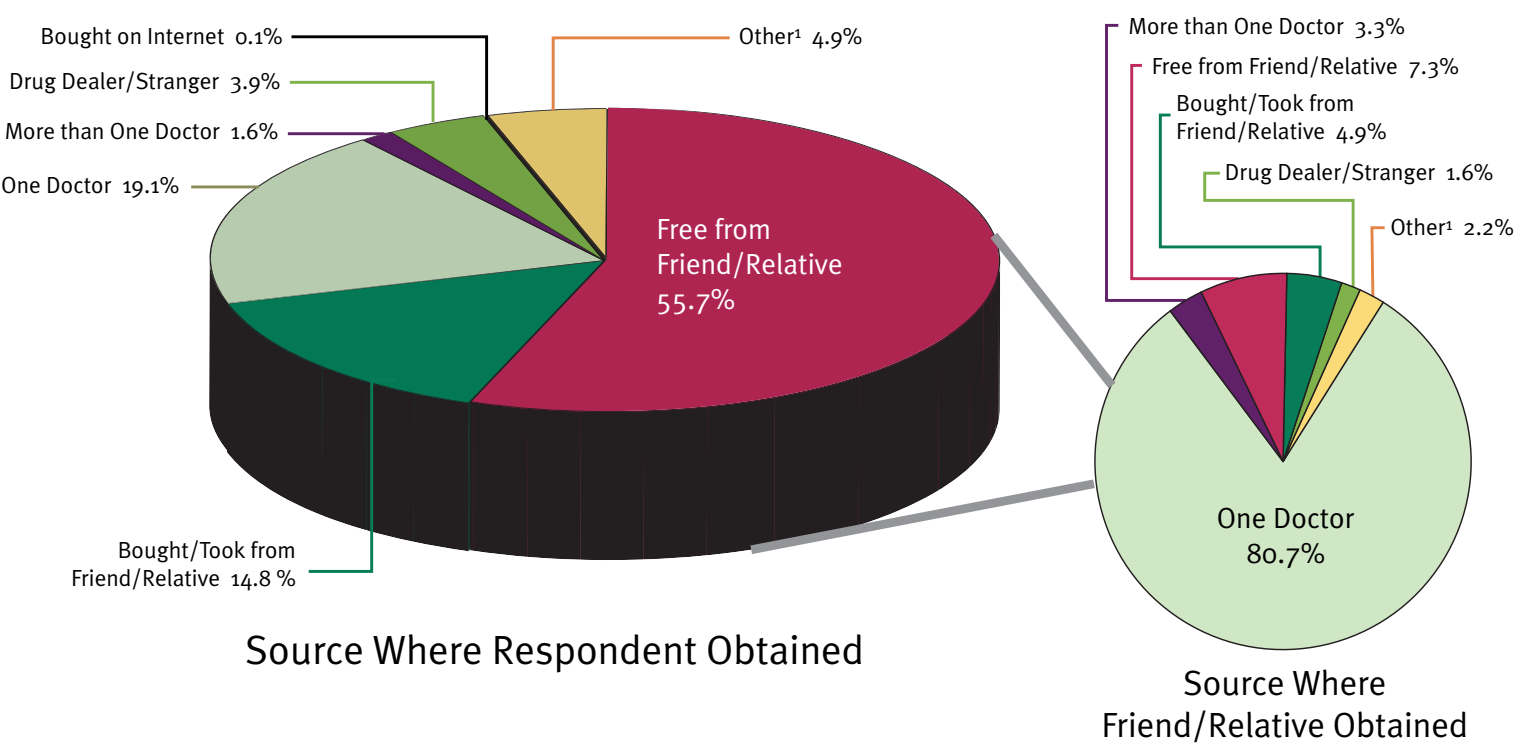

Note: Totals may not total to $100 \%$ because of rounding or because suppressed estimates are not shown.

${ }^{1}$ The Other category includes the sources: "Wrote Fake Prescription," "Stole from Doctor's Office/Clinic/Hospital/Pharmacy," and "Some Other Way."

Fig. 9. Where pain relievers were obtained for most recent nonmedical use among past year users aged 12 or older: 2006 . Source: www.oas.samhsa.gov/nsduh/2k6nsduh/2k6results.pdf

- Students high on drugs at school.

- Students drunk at school.

Essentially, this translates into startling facts that 16 million teens, which includes 11 million high schoolers and 5 million middle schoolers, are involved in drug use either with drug dealing and use, drug possession, or alcohol intoxication. The report shows that at least once a week, $22 \%$ of 12 to 17 year olds, or 5.7 million of the population, see drugs used or sold and students high or drunk on their school grounds.

It is no surprise that children who attend druginfested schools are more likely to use drugs. Children at drug-infested schools are 16 times more likely to use illegal drugs other than marijuana or prescription drugs, 15 times more likely to use prescription drugs to get high, 6 times more likely to get drunk in a typical month, 5 times more likely to have used marijuana, and 4 times more likely to have smoked cigarettes.

Over the past 6 years, since 2002, the proportion of students attending middle schools where drugs are used, kept, or sold has increased by $63 \%$ and the proportion of students attending high schools where drugs are used, kept, or sold has increased by $39 \%$. Since last year, the proportion of teens attending schools where drugs are used, kept, or sold is on the rise for all types of schools with public high schools showing a $16 \%$ increase, private high schools showing a $38 \%$ increase, public middle school showing a $45 \%$ increase, and private middle schools showing a $50 \%$ increase (89).

While parents with their attitudes and expectations can significantly influence teen behavior and substance abuse risk in schools, unfortunately $59 \%$ believe the goal of making their child's school drugfree is unrealistic, while only $41 \%$ considered this a realistic goal. Another misunderstanding in the minds of parents is that the vast majority of parents ( $86 \%)$ associate college with drinking; even then, relatively few believe that their teen will drink a lot while in college (89).

\section{Teen Risk Status}

The National Survey of American Attitudes on Substance Abuse (89) showed $56 \%$ of American teenagers aged 12 to 17 are at a significant substance abuse risk with $15 \%$ at high risk, $41 \%$ at moderate risk, and only $44 \%$ in the low risk category. 


\section{Exposure to Drugs}

Thirty-one percent of high school students, or more than 4 million, and $9 \%$ of middle school students (more than 1 million) have experienced the use of illegal drugs, the sale of illegal drugs, students high on drugs, or students being drunk at least once a week on their school grounds (89). Table 5 illustrates the percentage of teens witnessing various activities at school.

Teens at drug-infested schools are more likely to use illegal drugs. Further, these teens are 15 times likelier to have used prescription drugs to get high and 5 times likelier to have used marijuana. In addition, it was also shown that teen risk scores are higher at drug-infested schools.

Availability fuels drug abuse, and, unfortunately, it is far too easy to obtain drugs in schools. As is evident by the statistics, $37 \%$ of these teens state that they can buy marijuana within a day, and $17 \%$ admit that they can buy marijuana within an hour.

Drug abuse has taken a sharp and dangerous turn at schools where students think that "cool" kids use drugs or alcohol. In fact, $20 \%$ of the teens surveyed say that the most popular kids at their school have a reputation for using illegal drugs, and $52 \%$ of kids believe that the use of alcohol or illegal drugs is cool. Further analysis shows at drug-infested schools, $46 \%$ believe in drinking a lot and $33 \%$ believe in using illegal drugs, whereas at drug-free schools the proportion is $15 \%$ and $6 \%$ respectively. The survey also shows that teens who say they are among the most popular kids at their school are likely to use illicit drugs (40\% vs. $56 \%$ ).

Table 5. Percentage of teens, ages 12 to 17, who have witnessed the following at school* .

\begin{tabular}{||l|l||}
\hline Student Drug Possession & $48 \%$ \\
\hline Students High on Drugs & $43 \%$ \\
\hline Students Drunk & $29 \%$ \\
\hline Drug Use & $22 \%$ \\
\hline Drug Dealing & $18 \%$ \\
\hline
\end{tabular}

* These add to more than $100 \%$ as teens could have responded yes to more than 1 occurence.

Source: The National Center on Addiction and Substance Abuse. National survey of American attitudes on substance abuse XII: teens and parents. August 2007. www.casacolumbia.org/absolutenm/articlefiles/380-2007\%20Teen\%20 Survey\%20XII.pdf (89).
Startling statistics show that drugs and alcohol are abused irrespective of if students are in private or public schools and if they are in middle schools or high schools. Private schools are more likely to be drug-free than public schools, with $50 \%$ of the teens who attend public schools reporting that drugs are used, whereas only $32 \%$ of teens who attend private schools admit to it. In addition, smaller schools are more likely to be drug-free, with $38 \%$ of teens who attend schools with fewer than 1,000 students admitting to drug use in their school, whereas $60 \%$ of teens who attend schools with 1,000 or more students admitting to drug use in their school (89).

\section{Attitudes and Expectations of Parents}

Unfortunately, over half of the parents whose children attend schools where drugs are used believe that the goal of making their child's school drugfree is unrealistic (89). Consequently, teens whose parents believe it is a very unrealistic goal to make their child's school drug-free have substance abuse risk scores that are more than 2 times greater than those of teens whose parents say the goal of making their teens school drug-free is realistic $(1.58 \%$ vs. $0.59 \%)$.

Forty-one percent of parents believe it is not very likely that their teenager will use drugs and $17 \%$ believe that it will never happen. Only $39 \%$ say it is very or somewhat likely that their teenager will try an illegal drug in the future.

\section{Parent/Teen Disconnect}

Parents and teens have a disconnect with different concerns and opinions regarding the problem of drugs. When parents are asked what they think their teenager would say is the most important problem he or she faces, $45 \%$ of parents cite social pressures. Only $11 \%$ cite drugs, including alcohol. In contrast, when asked to identify the most important problem kids their age face, $24 \%$ of teens cite drugs, including alcohol. Since 1995, more teens have cited drugs, alcohol, and tobacco as their top concerns than they have cited any other matter, and twice as many teens cite this as a concern as do their parents (89). 


\section{Therapeutic Use of Opioids}

With the common occurrence of chronic pain in the United States, the ability of opioids to effectively and safely treat acute and cancer pain is one of several arguments that is used to support extending opioid treatment to patients with chronic pain, where there had previously been considerable caution based on fears of addiction (7). It is argued that physicians should be encouraged to prescribe opioids because they are indispensable for the treatment of pain and suffering, because uncontrolled pain may have deleterious physical effects, and because persistent pain destroys people's autonomy, dignity, and decision-making capacity $(6,7,89)$. Thus, due to politics and emotional issues involved with efforts to improve awareness and treatment of chronic pain, the availability of opioids has increased dramatically in the past few decades. At the same time that multiple side effects, drug abuse, and addiction are recognized by these proponents, they continue to promote extensive opioid use under the umbrella of undertreatment of pain. Consequently, in spite of the considerable controversy over the use of opioids for the treatment of chronic pain of noncancer origin, opioid use has been exploding.

Caudill-Slosberg et al (74) evaluated the role of opioid prescriptions for musculoskeletal pain in the United States and compared the practices from 1980 to 2000. They analyzed the National Ambulatory Medical Care Survey - nationally representative survey of visits to office-based physicians - using data from 1980 - 1981 and 1999 - 2000, evaluating over 130,000 visits. Opioids doubled for chronic pain from $8 \%$ to $16 \%$ and for acute pain the increase was from $8 \%$ to $11 \%$. In addition, they also showed that prescriptions of more potent opioids (hydrocodone, oxycodone, morphine) for chronic musculoskeletal pain increased from $2 \%$ to $9 \%$ in visits corresponding to 5.9 million visits in 2002 - an increase of 4.6 million visits from 1980. They concluded that while there was increased attention to pain treatment and opioid prescriptions sold, there was no increase in office visits for musculoskeletal pain complaints.

Vogt et al (75) evaluated analgesic usage for low back pain and its impact on healthcare costs and service use. In 2001, 55.5\% of members with claims for low back services received analgesics costing a total of $\$ 1.4$ million, of which $68 \%$ were opioids. They also found that opioid use was associated with the high volume usage of low back pain services and correlated with the higher use of opioids in patients with psycho- genic pain and low back pain related to orthopedic devices (fusion, etc.).

Luo et al (90) also evaluated patterns and trends in opioid use among individuals with back pain in the United States. They showed overall opioid use among $11.6 \%$ of individuals with back pain from a sample of 23.6 million in 1996 increasing to $12.6 \%$ in 1999 with a sample of 24.7 million individuals. The prescriptions showed an increase in oxycodone and hydrocodone with a decrease in propoxyphene.

A systematic review of opioid treatment for chronic back pain by Martell et al (32) showed variable prescribing patterns for opioids ranging from $3 \%$ to $66 \%$ for low back pain patients. They evaluated 11 studies describing the prevalence of opioid treatment for chronic back pain, most using a cross-sectional design. However, only 4 of the 11 studies, or approximately $36 \%$ of the studies, had reasonable quality rating scores of 12 or more out of a total of 27 (77-80). Prevalence estimates were highest in specialty treatment centers ranging from $11 \%$ to $66 \%$, and lowest in primary care centers ranging from $3 \%$ to $31 \%$.

In pain management settings, it has been reported that as many as $90 \%$ of the patients receive opioids for chronic pain management in spite of numerous issues involved (33-57). Further, it also has been shown that the majority of these patients were on opioids prior to presenting to an interventional pain management setting (33).

The therapeutic use of opioids has exploded in the United States, witnessed by increased sales of hydrocodone by 244\% from 1997 to 2006, whereas methadone usage increased $1177 \%$ and oxycodone increased $732 \%$ (Table 6 and Fig. 10). Overall, opioids increased from 50.7 million grams of medication in 1997 to 115.3 million grams of medication in 2006, an increase of $127 \%$. The estimated number of prescriptions filled for controlled substances increased from 222 million in 1994 to 354 million in $2003(3,11,12)$.

The milligram per person use of therapeutic opioids in the US increased from 73.59 milligrams in 1997 to 329.23 milligrams per person in 2006, an increase of $347 \%$ (Table 7 ). During the same period the therapeutic use of methadone increased by $1129 \% \mathrm{mg} / \mathrm{per}-$ son, and oxycodone by $899 \% \mathrm{mg} /$ person. This is also confirmed by the fact that between 1992 and 2002, the population of the United States increased by $13 \%$, whereas, the number of prescriptions written for noncontrolled drugs 
Table 6. Retail sales of opioid medications (grams of medication) from 1997 to 2006.

\begin{tabular}{|c|c|c|c|c|c|c|c|c|c|c|c|}
\hline Drug & 1997 & 1998 & 1999 & 2000 & 2001 & 2002 & 2003 & 2004 & 2005 & 2006 & \begin{tabular}{|c}
$\%$ of \\
Change \\
from \\
1997
\end{tabular} \\
\hline Methadone & 518,737 & $\begin{array}{c}692,675 \\
(34 \%) \\
\end{array}$ & $\begin{array}{c}964,982 \\
(39 \%)\end{array}$ & $\begin{array}{c}1,428,840^{*} \\
(48 \%)\end{array}$ & $\begin{array}{c}1,892,691 \\
(32 \%)\end{array}$ & $\begin{array}{c}2,649,559 \\
(40 \%) \\
\end{array}$ & $\begin{array}{c}3,683,881 \\
(39 \%)\end{array}$ & $\begin{array}{c}4,730,157 \\
(28 \%) \\
\end{array}$ & $\begin{array}{c}5,362,815 \\
(13 \%)\end{array}$ & $\begin{array}{c}6,621,687 \\
(23 \%)\end{array}$ & $1177 \%$ \\
\hline Oxycodone & $4,449,562$ & $\begin{array}{c}6,579,719 \\
(48 \%)\end{array}$ & $\begin{array}{c}9,717,600 \\
(48 \%)\end{array}$ & $\begin{array}{c}15,305,913 \\
(58 \%)\end{array}$ & $\begin{array}{c}19,927,286 \\
(30 \%)\end{array}$ & $\begin{array}{c}22,376,892 \\
(12 \%)\end{array}$ & $\begin{array}{c}26,655,152 \\
(19 \%)\end{array}$ & $\begin{array}{c}29,177,530 \\
(9 \%)\end{array}$ & $\begin{array}{c}30,628,973 \\
(5 \%)\end{array}$ & $\begin{array}{c}37,034,220 \\
(21 \%)\end{array}$ & $732 \%$ \\
\hline Fentanyl Base & 74,086 & $\begin{array}{l}90,618 \\
(22 \%)\end{array}$ & $\begin{array}{c}107,141 \\
(18 \%)\end{array}$ & $\begin{array}{c}146,612^{*} \\
(37 \%)\end{array}$ & $\begin{array}{c}186,083 \\
(27 \%)\end{array}$ & $\begin{array}{c}242,027 \\
(30 \%)\end{array}$ & $\begin{array}{c}317,200 \\
(31 \%)\end{array}$ & $\begin{array}{c}370,739 \\
(17 \%)\end{array}$ & $\begin{array}{c}387,928 \\
(5 \%)\end{array}$ & $\begin{array}{c}428,668 \\
(11 \%)\end{array}$ & $479 \%$ \\
\hline Hydromorphone & 241,078 & $\begin{array}{c}260,009 \\
(8 \%)\end{array}$ & $\begin{array}{c}292,506 \\
(12 \%)\end{array}$ & $\begin{array}{c}346,574^{*} \\
(18 \%)\end{array}$ & $\begin{array}{c}400,642 \\
(16 \%)\end{array}$ & $\begin{array}{c}473,362 \\
(18 \%)\end{array}$ & $\begin{array}{c}579,372 \\
(22 \%)\end{array}$ & $\begin{array}{c}655,395 \\
(13 \%)\end{array}$ & $\begin{array}{c}781,287 \\
(19 \%)\end{array}$ & $\begin{array}{c}901,663 \\
(15 \%\end{array}$ & $274 \%$ \\
\hline Hydrocodone & $8,669,311$ & $\begin{array}{c}10,389,503 \\
(20 \%) \\
\end{array}$ & $\begin{array}{c}12,101,621 \\
(16 \%)\end{array}$ & $\begin{array}{c}14,118,637 \\
(17 \%)\end{array}$ & $\begin{array}{c}15,594,692 \\
(10 \%)\end{array}$ & $\begin{array}{c}18,822,619 \\
(21 \%)\end{array}$ & $\begin{array}{c}22,342,174 \\
(19 \%) \\
\end{array}$ & $\begin{array}{c}24,081,900 \\
(8 \%)\end{array}$ & $\begin{array}{c}25,803,543 \\
(7 \%)\end{array}$ & $\begin{array}{c}29,856,368 \\
(16 \%)\end{array}$ & $244 \%$ \\
\hline Morphine & $5,922,872$ & $\begin{array}{c}6,408,322 \\
(8 \%)\end{array}$ & $\begin{array}{c}6,804,935 \\
(6 \%)\end{array}$ & $\begin{array}{c}7,807,511 \\
(15 \%)\end{array}$ & $\begin{array}{c}8,810,700 \\
(13 \%)\end{array}$ & $\begin{array}{c}10,264,264 \\
(16 \%)\end{array}$ & $\begin{array}{c}12,303,956 \\
(20 \%)\end{array}$ & $\begin{array}{c}14,319,243 \\
(16 \%)\end{array}$ & $\begin{array}{c}15,054,846 \\
(5 \%)\end{array}$ & $\begin{array}{c}17,507,148 \\
(16 \%)\end{array}$ & $196 \%$ \\
\hline Codeine & $25,071,410$ & $\begin{array}{c}26,018,054 \\
(4 \%)\end{array}$ & $\begin{array}{c}23,917,088 \\
(-8 \%)\end{array}$ & $\begin{array}{c}23,474,865^{*} \\
(-2 \%)\end{array}$ & $\begin{array}{c}23,032,641 \\
(-2 \%)\end{array}$ & $\begin{array}{c}22,633,733 \\
(-2 \%)\end{array}$ & $\begin{array}{c}21,865,409 \\
(-3 \%)\end{array}$ & $\begin{array}{c}20,264,555 \\
(-7 \%)\end{array}$ & $\begin{array}{c}18,960,038 \\
(-6 \%)\end{array}$ & $\begin{array}{c}18,762,919 \\
(-1 \%\end{array}$ & $-25 \%$ \\
\hline $\begin{array}{l}\text { Meperidine } \\
\text { (Pethidine) }\end{array}$ & $5,765,954$ & $\begin{array}{c}5,834,294 \\
(1 \%)\end{array}$ & $\begin{array}{c}5,539,592 \\
(-5 \%)\end{array}$ & $\begin{array}{c}5,494,898^{*} \\
(-1 \%)\end{array}$ & $\begin{array}{c}5,450,204 \\
(-1 \%)\end{array}$ & $\begin{array}{c}5,412,389 \\
(-1 \%)\end{array}$ & $\begin{array}{c}5,239,932 \\
(-3 \%)\end{array}$ & $\begin{array}{c}4,856,644 \\
(-7 \%)\end{array}$ & $\begin{array}{c}4,272,520 \\
(-12 \%)\end{array}$ & $\begin{array}{c}4,160,033 \\
(-3 \%)\end{array}$ & $-28 \%$ \\
\hline Total & $50,713,010$ & $\begin{array}{c}56,273,194 \\
(11 \%)\end{array}$ & $\begin{array}{c}59,445,465 \\
(6 \%)\end{array}$ & $\begin{array}{c}35,962,089.84 \\
(15 \%)\end{array}$ & $\begin{array}{c}75,294,939 \\
(11 \%)\end{array}$ & $\begin{array}{c}82,874,845 \\
(10 \%)\end{array}$ & $\begin{array}{c}92,987,076 \\
(12 \%)\end{array}$ & $\begin{array}{c}98,456,163 \\
(6 \%)\end{array}$ & $\begin{array}{c}101,251,950 \\
(6 \%)\end{array}$ & $\begin{array}{c}115,272,706 \\
(14 \%)\end{array}$ & $127 \%$ \\
\hline
\end{tabular}

Number in parenthesis is percentage of change from previous year.

* For year 2000 data is not available, the average of 1999 and 2001 was taken.

Source: http://www.deadiversion.usdoj.gov/arcos/retail_drug_summary/index.html Access date: 3/13/08

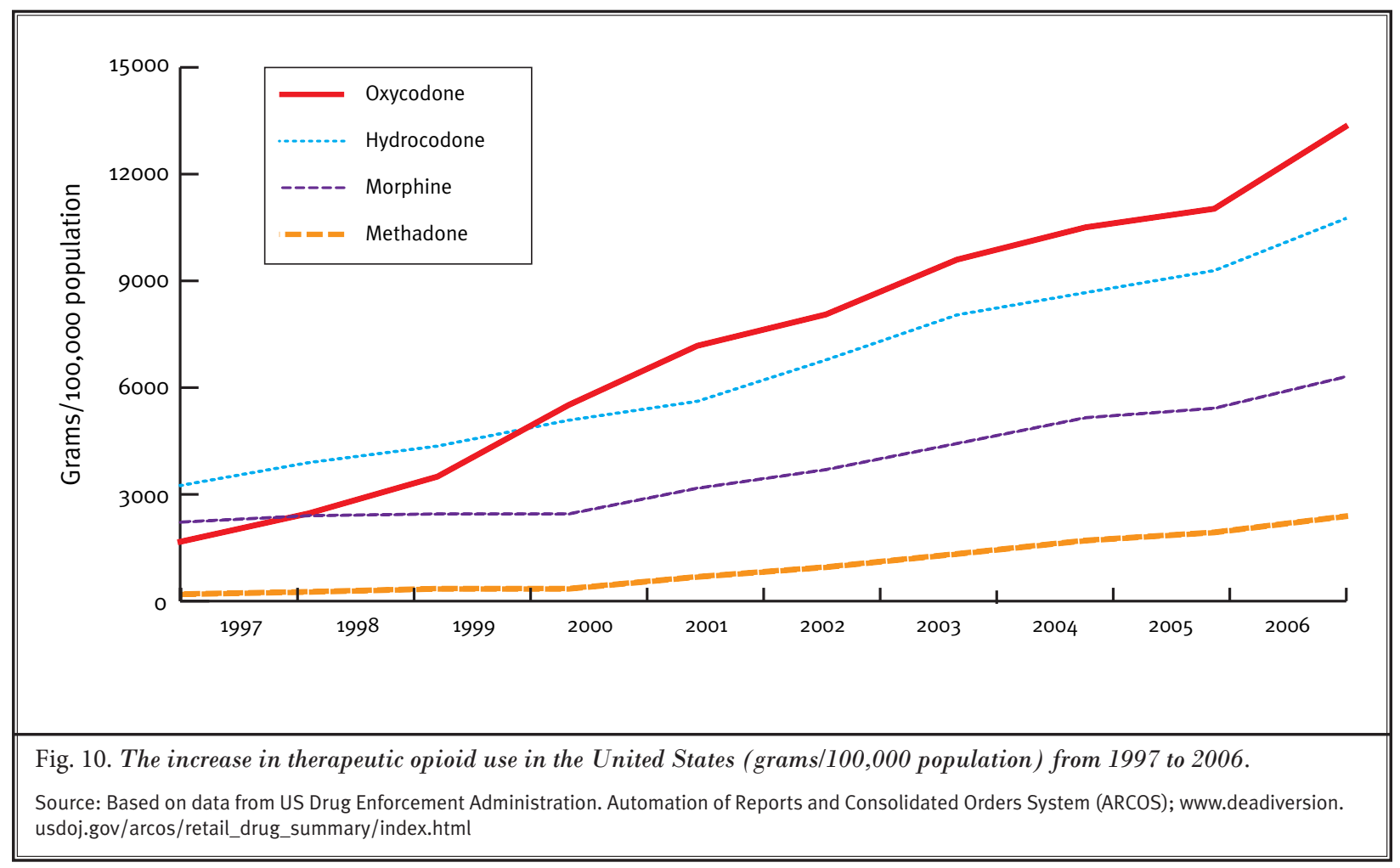


Therapeutic Opioid Use, Abuse, and Nonmedical Use

Table 7. The increase in therapeutic opioids use in the U.S. ( $\mathrm{mg} / \mathrm{person})$ from 1997 to 2006.

\begin{tabular}{|l|c|c|c|c|c|c|c|c|c|c|c||}
\hline \hline Type & $\mathbf{1 9 9 7}$ & $\mathbf{1 9 9 8}$ & $\mathbf{1 9 9 9}$ & $\mathbf{2 0 0 0}$ & $\mathbf{2 0 0 1}$ & $\mathbf{2 0 0 2}$ & $\mathbf{2 0 0 3}$ & $\mathbf{2 0 0 4}$ & $\mathbf{2 0 0 5}$ & $\mathbf{2 0 0 6}$ & $\begin{array}{c}\text { \% of Change } \\
\text { from 1997 }\end{array}$ \\
\hline Morphine & 22.20 & 24.01 & 24.50 & 28.11 & 31.72 & 36.95 & 44.30 & 51.55 & 54.20 & 63.03 & $184 \%$ \\
\hline Methadone & 1.94 & 2.60 & 3.47 & $5.14^{\star}$ & 6.81 & 9.54 & 13.26 & 17.03 & 19.31 & 23.84 & $1129 \%$ \\
\hline Oxycodone & 16.68 & 24.66 & 34.99 & 55.11 & 71.75 & 80.56 & 95.97 & 105.05 & 110.27 & 133.33 & $899 \%$ \\
\hline Hydrocodone & 32.49 & 38.93 & 43.57 & 50.83 & 56.15 & 67.77 & 80.44 & 86.70 & 92.90 & 107.49 & $231 \%$ \\
\hline Fentanyl & 0.28 & 0.34 & 0.39 & $0.53^{*}$ & 0.67 & 0.87 & 1.14 & 1.33 & 1.40 & 1.54 & $450 \%$ \\
\hline Total & $\mathbf{7 3 . 5 9}$ & $\mathbf{9 0 . 5 4}$ & $\mathbf{1 0 6 . 9 2}$ & $\mathbf{1 3 9 . 7 2}$ & $\mathbf{1 6 7 . 1}$ & $\mathbf{1 9 5 . 6 9}$ & $\mathbf{2 3 5 . 1 1}$ & $\mathbf{2 6 1 . 6 6}$ & $\mathbf{2 7 8}$ & $\mathbf{3 2 9 . 2 3}$ & $\mathbf{3 4 7 \%}$ \\
\hline
\end{tabular}

* For year 2000 data is not available, the average of 1999 and 2001 was taken.

Source: Data taken from U.S. Drug Enforcement Administration. Automation of Reports and Consolidated Orders System (ARCOS); www.deadiversion.usdoj. gov/arcos/retail_drug_summary/index.html. Access date: 3/13/08

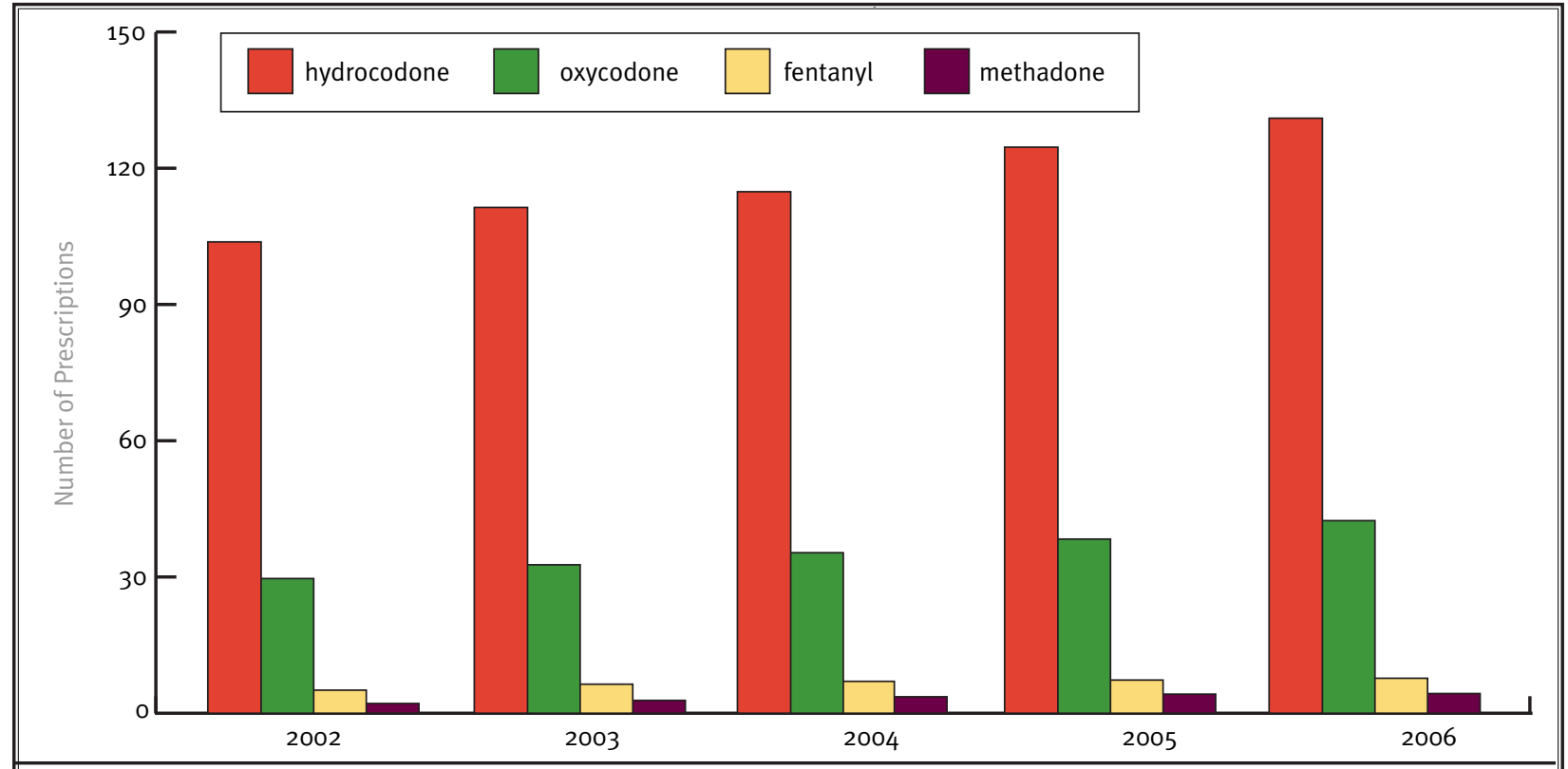

Fig. 11. Total prescriptions of selected narcotic analgesics (29).

Source: Methadone Morality Working Group Drug Enforecement Administration, Office of Diversion Control.

\section{Adverse Consequences}

Opioids are associated with some well-known common side effects including nausea, sedation, euphoria, dysphoria, constipation, and itching. However, with chronic use, a different breed of side effects develop which includes hormonal and immune system effects, abuse and addiction, tolerance, and hyperalgesia. More importantly, opioid use has been associated with increased disability, medical costs, subsequent surgery, and continued or late opioid use (72-76).

Vogt et al (75) reported an association between opioid prescribing and an increase in overall healthcare costs for low back pain, implying higher levels of utilization. Similarly Mahmud et al (76) found an association between opioid use for more than a week for acute low back pain and disability duration in a worker's compensation cohort. Webster et al (72) showed 
that patients receiving more than a $450 \mathrm{mg}$ equivalent of morphine over a period of several months were, on average, disabled 69 days longer than those who received no early opioids, had 3 times increased risk for surgery, and had 6 times greater risk of receiving late opioids. Fillingim et al (79) indicated that opioid use was associated with greater self-reported disability and poorer function.

An epidemiological study from Denmark (66), where opioids are prescribed liberally for chronic pain, demonstrated worse pain, higher healthcare utilization, and lower activity levels in opioid treated patients compared to a matched cohort of chronic pain patients not using opioids, suggesting that when opioids are prescribed liberally, even if some patients benefit, the overall population does not.

\section{Effectiveness of Opioid Treatment}

Multiple reviews have been published to evaluate the effectiveness of opioid therapy in chronic pain $(6,7,32,62-65)$. Martell et al (32) in their systematic review failed to conclude that opioids provide efficacy for chronic pain. Ballantyne (7), after directly comparing the efficacy of different opioids, concluded that a nonsignificant reduction in pain was present from baseline. Chou et al (62) concluded that there was insufficient and poor evidence to prove the safety or effectiveness of any opioids. Kalso et al (63) concluded that the mean decrease in pain intensity in most studies was at least $30 \%$ and at least $44 \%$ of the patients continued treatment between 7 and 24 months. Furlan et al (65) concluded that strong opioids were more effective with pain relief and functional outcomes; however, drop-out rates averaged $33 \%$.

Overall the evidence supporting the long-term analgesic efficacy is weak at best based on the present evidence. In addition, surprisingly, epidemiological studies are less positive with regards to function and quality of life and report the failure of opioids to improve quality of life in chronic pain patients (5-7,62-66).

\section{Prescription Opioid Abuse}

Prescription opioids are abused among the populations with or without pain, and in patients receiving or not receiving opioids. The abuse is associated with substantial risks to the patients and the nation as a whole with increasing emergency department visits, deaths, and federal drug spending.

\section{Controlled Substances Abuse in Chronic Pain}

Opioids are by far the most abused drugs, especially in chronic pain settings. Other controlled substances including benzodiazepines, sedative-hypnotics, and central nervous system stimulants, though described as having less potential for abuse, are also of major concern. Numerous investigations $(3,4,32-50,60,61,87)$ have illustrated drug abuse in $18 \%$ to $41 \%$ in patients receiving opioids for chronic pain.

Martell et al (32), in a systematic review of opioid treatment for chronic back pain, estimated the prevalence of lifetime substance use disorders to range from $36 \%$ to $56 \%$, with an astounding estimate of $43 \%$ current substance use disorders. Sadly, aberrant medication-taking behaviors also ranged from $5 \%$ to $24 \%$.

Chronic pain patients may not only abuse controlled substances by doctor shopping, etc., but they may also abuse or use illicit drugs in conjunction with controlled substances. Multiple investigators have studied the issue of illicit drug use in chronic pain patients receiving controlled substances (35-50). The results showed that illicit drug use in patients without controlled substance abuse was found in $14 \%$ to $16 \%$ of patients, and illicit drug use in patients with controlled substance abuse was present in $34 \%$ of the patients $(35,37,38)$. In addition, illicit drug use was significant in chronic pain patients in general, and was also similar in patients using either long-acting or short-acting opioids (48). In other evaluations, it was shown that enhanced adherence monitoring will in fact decrease controlled substance abuse and illicit drug use $(45,50)$.

Along with the increase of prescriptions for controlled drugs from 1992 to 2002 of 154\% (67-69), there was also a $90 \%$ increase in the number of people who admitted abusing controlled prescription drugs. Mahowald et al (77) and White et al (91) evaluated opioid abuse in the insured population of the United States. Opioid abuse was determined to be present in 6.7 to 8 per 10,000 persons insured. However, opioid abusers also presented with multiple comorbidities and expenses 8 times higher than for nonabusers ( $\$ 15,884$ vs. $\$ 1,830$ ).

The cost of opioid abuse is enormous. The White House Budget Office estimated drug abuse costs to the US Government to be approximately $\$ 300$ billion a year $(3,4)$. The White House Office of National Drug Control Policy (ONDCP), a component of the Executive Office of the President, established by the Anti-Drug Abuse Act of 1998, has been spending $\$ 12-13$ billion each year. 


\section{Emergency Department Visits}

The Drug Abuse Warning Network (DAWN) publishes results of emergency department visits with drug misuse and abuse. In 2005, DAWN (18) published results with 816,696 emergency department visits involving an illicit drug. Of these, a majority, or 598,542 visits, were secondary to nonmedical use of prescription or over-the-counter pharmaceuticals or dietary supplements. Among these commonly reported substances, psychotherapeutic agents constituted $46 \%$ and central nervous system agents constituted $51 \%$ of the visits. Further, among the CNS agents the most frequent were opiates/opioid analgesics at $33 \%$ and methadone, oxycodone, and hydrocodone were the most frequent of these opioids:

- Hydrocodone/combinations in 51,225 ED visits (Cl: 37,416-65,033),

- Oxycodone/combinations in 42,810 ED visits (Cl: $30,672-54,948)$, and

- Methadone in 41,216 ED visits (Cl: 29,249-53,184). Emergency department visits for narcotics were 160,363 in 2005 compared to 42,857 in 1995 , a $274 \%$ increase over a period of 11 years (Fig. 12). Among the psychotherapeutic agents, the anxiolytics (anti-anxiety agents, sedatives, and hypnotics) were the most frequent, occurring in $34 \%$ of the visits associated with nonmedical use of pharmaceuticals (4). DAWN estimated that 172,388 ED visits were associated with nonmedical use of pharmaceuticals involving benzodiazepines in 2005, compared to 71,609 in 1995 , a $141 \%$ increase over a period of 11 years (18-20).

\section{Increasing Deaths}

Controlled substance abuse is not only associated with increasing costs, doctor shopping, theft, and emergency department visits, but also with deaths. Mortality data is obtained from DAWN Medical Examiner Reports (92), National Forensic Laboratory Information System (93), and National Center for Health Statistics $(23,24,26,27)$.

\section{National Center for Health Statistics}

Reporting on unintentional drug poisoning mortality rates in the United States, Paulozzi et al (23) showed startling results with increasing deaths due

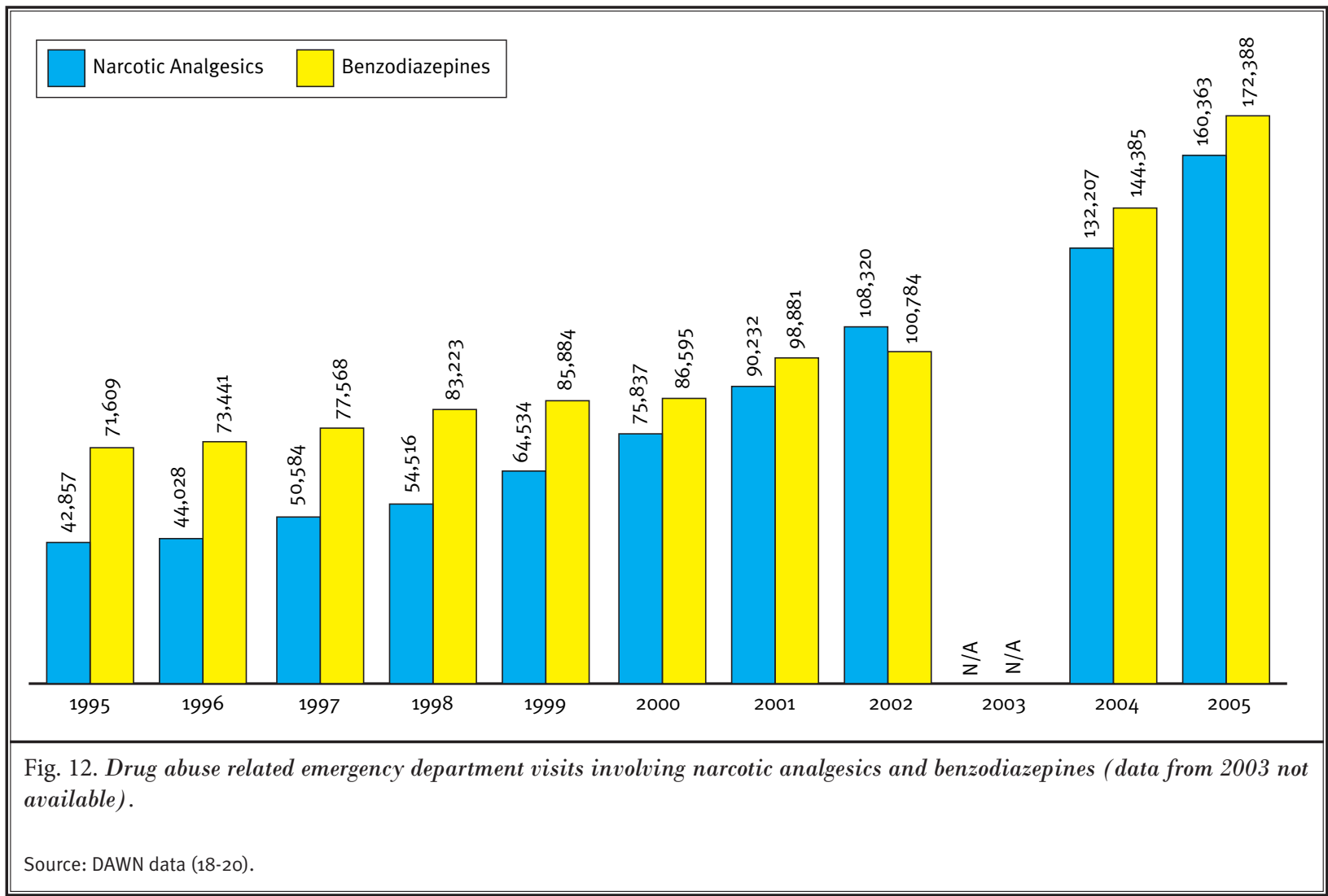


to prescription opioids exceeding heroin and cocaine poisonings, with increased deaths matching the increased supply of opioids for each drug. Between 1999 and 2002 the number of opioid analgesic poisonings on death certificates increased $91.2 \%$ while heroin and cocaine poisoning increased $12.4 \%$ and $22.8 \%$, with opioid analgesic poisonings listed in 5,528 deaths - more than either heroin or cocaine. In contrast, unintentional drug poisoning mortality rates increased on average 5.3\% per year from 1979 to 1990 , whereas the increase was $18.1 \%$ per year from 1990 to 2002.

In another report evaluating morbidity and mortality in February 2007, Paulozzi (24) revealed further startling facts and demonstrated that unintentional drug poisoning was second only to motor-vehicle crashes as the cause of death from unintentional injury in the United States. This updated study showed the number of unintentional poisoning deaths increased from 12,186 in 1999 to 20,950 in 2004, with an increase of age adjusted rate of $62.5 \%$ from 4.4 per 100,000 population in 1990 to 7.1 in 2004 . The highest rate of deaths $(59.6 \%)$ in 2004 were among persons aged 35 to 54 years. Among the opioids, methadone has been implicated in more unintentional poisoning deaths than any other opioid (25-27).

In an evaluation by the Office of Analysis and Epidemiology (24), methadone-related deaths from 1999 to 2004 increased $390 \%$, whereas the number of all poisoning deaths increased $54 \%$. Further, poisoning deaths mentioning methadone increased from $4 \%$ of all poisoning deaths to $13 \%$ of all poisoning deaths. It was also shown that while all poisoning deaths increased 6\% from 2002 to 2004, methadone deaths increased $29 \%$ (Table 8 ). The largest increases of deaths were noted in persons aged 15 to 24 years with a rate 11 times that of 1999 in 2004, even though most methadone deaths were in persons aged 35 to 44 and 45 to 54 years.

A reassessment of methadone mortality in 2007 $(29,30)$ concluded that all available data indicated that methadone continues to be increasingly used, misused, diverted, and abused. Further, significant increases in methadone-related deaths are being reported which, in some areas, are outpacing other narcotics. On November 27, 2006, the Food and Drug Administration, in its public health advisory, warned that methadone use in pain control may result in death and life-threatening changes in breathing and heartbeat (94). Current methadone use continues to climb, and from 1998 through 2006, has increased by about $250 \%$. Prescriptions for methadone have increased by nearly 700\% from 1998 through 2006. Figure 13 illustrates the methadone distribution business activity comparison between narcotic treatment programs, pharmacies, hospitals, and practitioners.

Table 8. Number of poisoning deaths in which specific narcotic substances are mentioned, 1999 to 2004.

\begin{tabular}{|c|c|c|c|c|c|c|c|c|}
\hline Substance & 1999 & 2000 & 2001 & 2002 & 2003 & 2004 & 1999-2004 & 2003-2004 \\
\hline & & & & & & & \multicolumn{2}{|c|}{ Percent change } \\
\hline $\begin{array}{l}\text { Poisoning by all Narcotics and } \\
\text { Psychodysleptics }\end{array}$ & 9,995 & 10,173 & 11,480 & 14,247 & 15,731 & 16,735 & 68.1 & 6.4 \\
\hline Opium & 4 & 2 & 5 & 3 & 4 & 1 & -75.0 & -75.0 \\
\hline Heroin & 1,964 & 1,846 & 1,782 & 2,091 & 2,080 & 1,881 & -4.2 & -9.6 \\
\hline Other Opioids & 2,757 & 2,932 & 3,484 & 4,431 & 4,877 & 5,242 & 90.1 & 7.5 \\
\hline Methadone & 786 & 988 & 1,456 & 2,360 & 2,974 & 3,849 & 389.7 & 29.4 \\
\hline Other Synthetic Narcotics & 732 & 784 & 962 & 1,301 & 1,406 & 1,668 & 127.9 & 18.6 \\
\hline Cocaine & 3,832 & 3,565 & 3,840 & 4,612 & 5,212 & 5,461 & 42.5 & 4.8 \\
\hline Other Narcotics & 2,902 & 2,880 & 2,881 & 3,143 & 3,117 & 2,761 & -4.9 & -11.4 \\
\hline Cannabis & 37 & 41 & 37 & 50 & 61 & 99 & 167.6 & 62.3 \\
\hline LSD & 3 & 3 & 2 & 0 & 1 & 1 & -66.7 & 0.0 \\
\hline Other & 9 & 8 & 7 & 5 & 6 & 5 & -44.4 & -16.7 \\
\hline
\end{tabular}

Note: Substance-specific data are not additive because a death certificate could have multiple drugs listed.

Source: National Center for Health Statistics, National Vital Statistics System (26). 


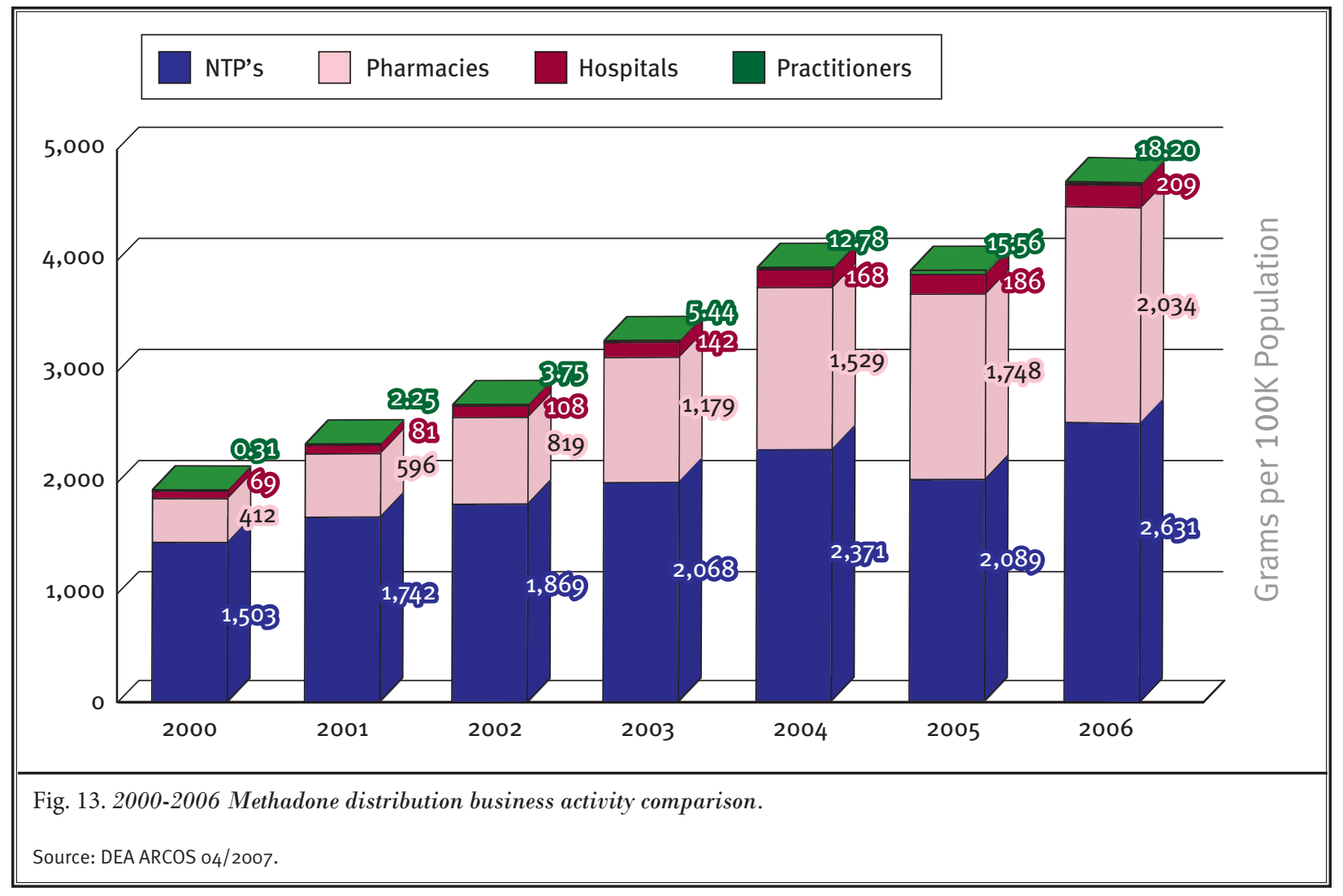

\section{National Forensic Laboratory Information System}

The National Forensic Laboratory Information System (NFLIS), sponsored by the Drug Enforcement Administration (DEA), is a program that systematically collects results from toxicological analysis conducted by state and local forensic laboratories on substances seized in law enforcement operations. Between 2001 and 2005, narcotic analgesics and benzodiazepines represented nearly $5 \%$ of all drugs analyzed (93). In comparison, in 2005, 33\% of all exhibits were cannabis and $32 \%$ were cocaine. Alprazolam, hydrocodone, and oxycodone were the most commonly reported controlled prescription drugs, accounting for nearly $63 \%$ of all narcotic analgesics and benzodiazepines reported. From 2002 to 2006 methadone exhibits increased $170 \%$. In addition, methadone was more likely to be involved in illicit activities, meaning diverted and abused, than either hydrocodone or oxycodone.

\section{DAWN Medical Examiner Reports}

The DAWN Medical Examiner Reports, also known as DAWN ME, include deaths directly caused by drug use, misuse, or abuse, as well as deaths where the drug use, misuse, or abuse contributed to the death but did not cause it. The numbers are representative only of the locales for which they are reported and cannot be extrapolated nationwide (92). In the 6 states that participated in the mortality component of the Drug Abuse Warning Network, the rates of opiate related drug misuse deaths in 2003 ranged from 7.2 to 11.6 per 100,000 population. The 6 states participating in the mortality component of the DAWN were Maine, New Hampshire, Vermont, Maryland, Utah, and New Mexico. Death rates were lowest in New Hampshire and highest in New Mexico. Further, most opiate related drug misuse deaths involved multiple drugs in each of these 6 states. This evaluation also showed adults aged 35 to 54 had the highest rates of opioid misuse deaths in 5 of the 6 states except for Maine, where the highest rate was for adults aged 21 to 34 . Figure 14 illustrates state population and opiate related drug misuse deaths. Table 9 illustrates involvement of oxycodone, hydrocodone, and methadone in opiate misuse deaths in 2003. 


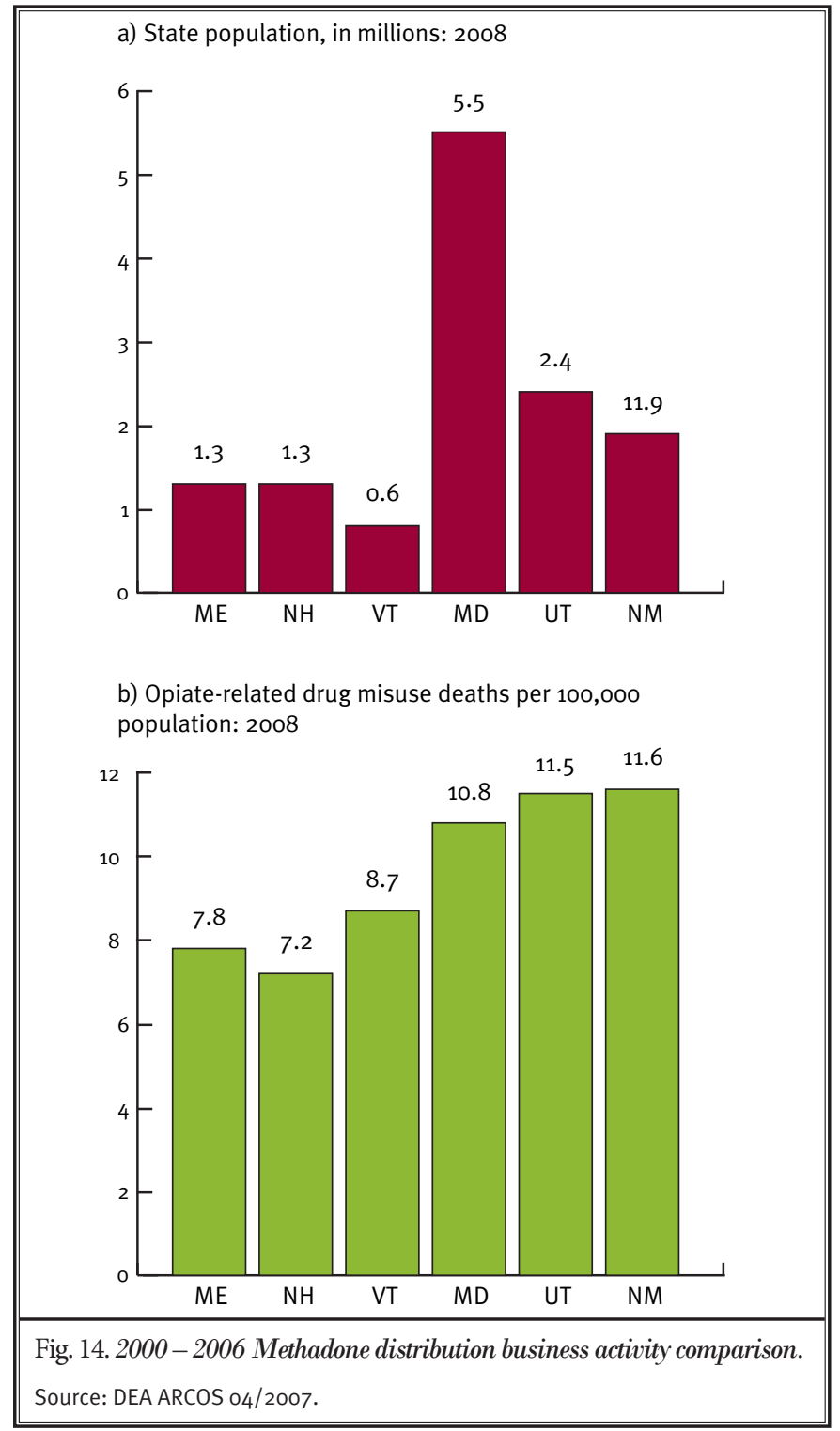

\section{Deaths Due to Psychotherapeutic Drugs in Interventional Pain Management Practices}

The literature on prevalence of deaths in pain management or specifically interventional pain management settings is not available.

\section{Conclusions}

Based on the data provided in this review, it appears that there has been an escalation over the past 10 years not only of the therapeutic use of opioids and other psychotherapeutics, but of their abuse and non-medical use as well. Because hydrocodone has become the number one prescribed medication in America, it is not hard to see the huge impact that would have on the overall patterns of abuse and nonmedical use, especially since the illicit use of prescribed psychotherapeutics (including opioids, which are at the top of the list) now overshadows the use of nonprescription illicit drugs, and drug dealers are no longer the primary source of illicit drugs. Diversion through family and friends is now our greatest enemy and their source is more likely to be from 1 physician and not from doctor shopping.

And we cannot overlook the highly interactive pattern of effect and impact that is produced in the general areas of substance abuse, mental health, and overall healthcare. Because of the close interrelationship between mental disorders and substance abuse, "dual diagnosis" is becoming more prevalent. The question, of course, is the age-old chicken-or-the-egg question: which comes first? We will probably never know.

In the meantime, we are clearly challenged to be aware of the difficulties presented by the

Table 9. Involvement of oxycodone, hydrocodone, and methadone in opiate misuse deaths: 2003.

\begin{tabular}{|l|c|c|c|c|c|c|c|}
\hline \multirow{2}{*}{ State } & \multicolumn{2}{|c|}{ Oxycodone } & \multicolumn{2}{c|}{ Hydrocodone } & \multicolumn{2}{c|}{ Methadone } & \multirow{2}{*}{ Total Opiate Misuse Deaths } \\
\cline { 2 - 7 } & Deaths & Percent & Deaths & Percent & Deaths & Percent & \\
\hline Maine & 24 & $24 \%$ & 7 & $7 \%$ & 47 & $46 \%$ & $37 \%$ \\
\hline New Hampshire & 19 & $20 \%$ & 7 & $8 \%$ & 34 & 12 & 53 \\
\hline Vermont & 16 & $30 \%$ & 8 & $15 \%$ & 12 & $22 \%$ & 595 \\
\hline Maryland & 86 & $14 \%$ & 15 & $3 \%$ & 142 & $24 \%$ & 270 \\
\hline Utah & 72 & $27 \%$ & 47 & $17 \%$ & 93 & $34 \%$ & 218 \\
\hline New Mexico & 29 & $13 \%$ & 22 & $10 \%$ & 36 & $17 \%$ & \\
\hline
\end{tabular}

Source: Substance Abuse and Mental Health Services Administration, Office of Applied Studies (2006). Opiate-related drug misuse deaths in 6 states: 2003. The New DAWN Report, issue 19. 
increased use of therapeutic opioids and to remember the physician's dictum: Do no harm. The alarming patterns described in this article require us as physicians to stop and ponder; to reflect upon our responsibilities; to ask ourselves what we can do to mitigate these problems; to investigate in more depth the real therapeutic advantages of opioid use, especially for chronic pain; to be more conservative in our therapeutic use of opioids; to invent newer strategies for the prevention of diversion; and most importantly, to be more proactive in educating our patients, their families, our congressional representatives and the public of the limitations of therapeutic use, and the dangers of abuse and non-medical use of opioids, and we must do so now.

\section{Acknowledgments}

The authors wish to thank Tonie M. Hatton and Diane E. Neihoff, transcriptionists, and Vidyasagar Pampati, MSc, for their assistance in the preparation of this manuscript. We are also grateful to the editors of Pain Physician for their comprehensive review and constructive criticism, assisting in improvements of this manuscript.

\section{References}

1. Substance Abuse and Mental Health Services Administration (2007). Results from the 2006 National Survey on Drug Use and Health: National Findings. (Office of Applied Studies, NSDUH Series H-32, DHHS Publication No. SMA 074293). Rockville, MD. www.oas.samh sa.gov/nsduh/2k6nsduh/2k6results. pdf

2. Manchikanti L, Whitfield E, Pallone F. Evolution of the National All Schedules Prescription Electronic Reporting Act (NASPER): A public law for balancing treatment of pain and drug abuse and diversion. Pain Physician 2005; 8:335347.

3. Manchikanti L. Prescription drug abuse: What is being done to address this new drug epidemic? Testimony before the Subcommittee on Criminal Justice, Drug Policy, and Human Resources. Pain Physician 2006; 9:287-321.

4. Manchikanti L. National drug control policy and prescription drug abuse: Facts and fallacies. Pain Physician 2007; 10:399-424.

5. Trescot AM, Boswell MV, Atluri SL, Hansen HC, Deer TR, Abdi S, Jasper JF, Singh $V$, Jordan AE, Johnson BW, Cicala RS, Dunbar EE, Helm II S, Varley KG, Such$\operatorname{dev}$ PK, Swicegood JR, Calodney AK, Ogoke BA, Minore WS, Manchikanti L. Opioid guidelines in the management of chronic non-cancer pain. Pain Physician 2006; 9:1-40.
6. Ballantyne JC, Mao J. Opioid therapy for chronic pain. N Engl J Med 2003; 349:1943-1953.

7. Ballantyne JC. Opioid analgesia: Perspectives on right use and utility. Pain Physician 2007; 10:479-491.

8. Califano JA. High Society: How Substance Abuse Ravages America and What to Do About It. Perseus Publishing, New York, 2007.

9. Kuehn BM. Opioid prescriptions soar: Increase in legitimate use as well as abuse. JAMA 2007; 297:249-251.

10. United Nations Office on Drugs and Crime. 2007 World Drug Report.

11. www.deadiversion.usdoj.gov/arcos/retail_drug_summary/index.htmo

12. Testimony of Nora D. Volkow, M.D., Director, National Institute on Drug Abuse, National Institutes of Health, U.S. Department of Health and Human Services, before the Subcommittee on Criminal Justice, Drug Policy, and Human Resources Committee, July 26, 2006.

13. Substance Abuse and Mental Health Services Administration (2006). Results from the 2005 National Survey on Drug Use and Health: National Findings. (Office of Applied Studies, NSDUH Series H-30, DHHS Publication No. SMA 064194). Rockville, MD. www.oas.samh sa.gov/nsduh/2k5nsduh/2k5Results. pdf

14. Substance Abuse and Mental Health Services Administration (2005). Over- view of Findings from the 2004 National Survey on Drug Use and Health. (Office of Applied Studies, NSDUH Series H-27, DHHS Publication No. SMA 054061). Rockville, MD. www.oas.samhsa. govNSDUH/2k4NSDUH/2k4Overview. pdf

15. Substance Abuse and Mental Health Services Administration (2004). Overview of Findings from the $2003 \mathrm{Na}$ tional Survey on Drug Use and Health. (Office of Applied Studies, NSDUH Series $\mathrm{H}-24$, DHHS Publication No. SMA 04-3963). Rockville, MD. www.oas. samhsa.gov/NHSDA/2k3NSDUH/ 2k3OverviewW.pdf

16. Substance Abuse and Mental Health Services Administration (2003). Overview of Findings from the $2002 \mathrm{Na}$ tional Survey on Drug Use and Health. (Office of Applied Studies, NSDUH Series H-21, DHHS Publication No. SMA 03-3774). Rockville, MD. www.oas. samhsa.gov/NHSDA/2k2NSDUH/ 2k2SoFOverviewW.pdf

17. Substance Abuse and Mental Health Services Administration (2002). Results from the 2001 National Household Survey on Drug Abuse: Volume I. Summary of National Findings. (Office of Applied Studies, NHSDA Series H-17, DHHS Publication No. SMA 02-3758). Rockville, MD. www.oas.samhsa.gov/ nhsda/2k1nhsda/PDF/cover.pdf

18. Drug Abuse Warning Network, 2005: National Estimates of Drug-Related 
Emergency Department Visits. DAWN Series D-29, DHHS Publication No. (SMA) 07-4256, Rockville, MD, March 2007. dawninfo.samhsa.gov/pubs/ed pubs/default.asp

19. Drug Abuse Warning Network, 2004: National Estimates of Drug-Related Emergency Department Visits DAWN Series D-28, DHHS Publication No. (SMA) 06-4143, Rockville, MD, April 2006. dawninfo.samhsa.gov/pubs/ed pubs/default.asp

20. Drug Abuse Warning Network, 2003: Interim National Estimates of Drug-related Emergency Department Visits DAWN Series D-26, DHHS Publication No. (SMA) 04-3972, Rockville, MD, December 2004. dawninfo.samhsa.gov/ pubs/edpubs/default.asp

21. US Department of Health and Human Services. Office of Applied Studies, Substance Abuse and Mental Health Services Administration (SAMHSA) Drug Abuse Warning Network. The DAWN Report. Narcotic analgesics, 2002 update. September 2004.

22. US Department of Health and Human Services. Office of Applied Studies, Substance Abuse, and Mental Health Services Administration (SAMHSA). Drug Abuse Warning Network. The DAWN Report. Benzodiazepines in drug abuse-related emergency department visits, 1995-2002. April 2004.

23. Paulozzi LJ, Budnitz DS, Xi Y. Increasing deaths from opioid analgesics in the United States. Pharmacoepidemiol Drug Saf 2006; 15:618-627.

24. Paulozzi L. Unintentional poisoning deaths - United States, 1999 - 2004. Centers for Disease Control and Prevention. MMWR Morb Mortal Wkly Rep 2007; 56:93-96. www.cdc.gov/mmwr/ preview/mmwrhtml/mm5605a1.htm

25. U.S. Department of Health and Human Services. Substance Abuse and Mental Health Services Administration, Center for Substance Abuse Treatment, Division of Pharmacologic Therapies. Methadone-Associated Mortality: Report of a National Assessment. dpt. samhsa.gov/reports/index.htm.

26. Fingerhut LA. Increases in methadonerelated deaths: 1999 - 2004. Health EStats. Hyattsville, MD: National Center for Health Statistics; 2006. www. cdc.gov/nchs/products/pubs/pubd/ hestats/methadone1999-04/metha done1999-04.htm
27. Centers for Disease Control and Prevention (CDC). Unintentional and undetermined poisoning deaths - 11 states, 1990 - 2001. MMWR Morb Mortal Wkly Rep 2004; 53:233-238.

28. Hughes AA, Bogdan GM, Dart RC. Active surveillance of abused and misused prescription opioids using poison center data: A pilot study and descriptive comparison. Clin Toxicol (Phila) 2007; 45:144-151.

29. Methadone Mortality Working Group Drug Enforcement Administration, Office of Diversion Control, April 2007.

30. US Department of Health and Human Services. Substance Abuse and Mental Health Services Administration (SAMH SA). Background Information for Methadone Mortality - A Reassessment. Sponsored by the Center for Substance Abuse Treatment, Substance Abuse, and Mental Health Services Administration. Washington, DC. July 20, 2007.

31. GAO Report. United States General Accounting Office. Prescription Drugs. OxyContin Abuse and Diversion and Efforts to Address the Problem. GAO Publication No. GAO-4-110, December 2003.

32. Martell BA, O'Connor PG, Kerns RD, Beck WC, Morales KH, Kosten TR, Fiellen DA. Systematic review: Opioid treatment for chronic back pain: Prevalence, efficacy, and association with addiction. Ann Intern Med 2007; 146:116-127.

33. Manchikanti L, Damron KS, McManus CD, Barnhill RC. Patterns of illicit drug use and opioid abuse in patients with chronic pain at initial evaluation: A prospective, observational study. Pain Physician 2004; 7:431-437.

34. Fishbain DA, Rosomoff HL, Rosomoff RS. Drug abuse, dependence, and addiction in chronic pain patients. Clin Pain 1992; 8:77-85.

35. Manchikanti L, Pampati V, Damron KS, Beyer CD, Barnhill RC, Fellows B. Prevalence of prescription drug abuse and dependency in patients with chronic pain in western Kentucky. I KY Med Assoc 2003; 101:511-517.

36. Manchikanti L, Damron KS, Pampati V, McManus CD. Prevalence of illicit drug use among individuals with chronic pain in the Commonwealth of Kentucky: An evaluation of patterns and trends. $J$ Ky Med Assoc 2005; 103:55-62.

37. Manchikanti L, Damron KS, Beyer CD, Pampati V. A comparative evaluation of illicit drug use in patients with or without controlled substance abuse in interventional pain management. Pain Physician 2003; 6:281-285.

38. Manchikanti L, Pampati V, Damron KS, Beyer CD, Barnhill RC. Prevalence of illicit drug use in patients without controlled substance abuse in interventional pain management. Pain Physician 2003; 6:173-178.

39. Manchikanti L, Manchukonda R, Pampati V, Damron KS, Brandon DE, Cash $K A, M c M a n u s C D$. Does random urine drug testing reduce illicit drug use in chronic pain patients receiving opioids? Pain Physician 2006; 9:123-129.

40. Vaglienti RM, Huber SJ, Noel KR, Johnstone RE. Misuse of prescribed controlled substances defined by urinalysis. WV Med J 2003; 99:67-70.

41. Katz NP, Sherburne S, Beach M, Rose RJ, Vielguth J, Bradley J, Fanciullo GJ. Behavioral monitoring and urine toxicology testing in patients receiving long-term opioid therapy. Anesth Analg 2003; 97:1097-1102.

42. Passik SD, Kirsh KL, McDonald MV, Ahn S, Russak SM, Martin L, Rosenfeld B, Breitbart WS, Portenoy RK. A pilot survey of aberrant drug-taking attitudes and behaviors in samples of cancer and AIDS patients. J Pain Symptom Manage 2000; 19:274-286.

43. Michna E, Jamison RN, Pham LD, Ross EL, Nedeljkovic SS, Narang S, Palombi $D$, Wasan AD. Urine toxicology screening among chronic pain patients on opioid therapy: Frequency and predictability of abnormal findings. Clin J Pain 2007; 23:173-179.

44. Manchikanti L, Damron KS, Pampati V, McManus CD, Weaver SE. Prospective evaluation of patients with increasing opiate needs: Prescription opiate abuse and illicit drug use. Pain Physician 2004; 7:339-344.

45. Manchikanti L, Cash KA, Damron KS, Manchukonda R, Pampati V, McManus CD. Controlled substance abuse and illicit drug use in chronic pain patients: An evaluation of multiple variables. Pain Physician 2006; 9:215-226.

46. Manchikanti L, Giordano J, Fellows B, Manchukonda R, Pampati V. Psychological factors as predictors of opioid abuse and illicit drug use in chronic pain patients. J Opioid Manage 2007; 3:89-100.

47. Ives TJ, Chelminski PR, Hammett-Sta- 
bler CA, Malone RM, Perhac JS, Potisek NM, Shilliday BB, DeWalt DA, Pignone MP. Predictors of opioid misuse in patients with chronic pain: A prospective cohort study. BMC Health Serv Res 2006; 6:46.

48. Manchikanti L, Manchukonda R, Pampati V, Damron KS. Evaluation of abuse of prescription and illicit drugs in chronic pain patients receiving short-acting (hydrocodone) or long-acting (methadone) opioids. Pain Physician 2005; 8:257-261.

49. Manchikanti L, Pampati V, Damron KS, McManus CD. Evaluation of variables in illicit drug use: Does a controlled substance abuse screening tool identify illicit drug use? Pain Physician 2004; 7:71-75.

50. Manchikanti L, Manchukonda R, Damron KS, Brandon D, McManus CD, Cash $K A$. Does adherence monitoring reduce controlled substance abuse in chronic pain patients? Pain Physician 2006; 9:57-60.

51. Substance Abuse and Mental Health Services Administration, Office of Applied Studies (April 6, 2007). The NSDUH Report: Patterns and Trends in Nonmedical Prescription Pain Reliever Use: 2002 to 2005. Rockville, MD. http://oas.samhsa.gov/2k7/pain/ pain.htm

52. Office of National Drug Control Policy Executive Office of the President. Teens and prescription drugs. An analysis of recent trends on the emerging drug threat. February 2007. www.the antidrug.com/pdfs/TEENS_AND_PRE SCRIPTION_DRUGS.pdf

53. Monitoring the Future (MTF), National Institute on Drug Abuse (NIDA). 2006. www.monitoringthefuture.org/pubs/ monographs/overview2006.pdf

54. Partnership for a Drug-Free America, The Partnership Attitude Tracking Study (PATS): Teens in grades 7 through 12, 2005. May 16, 2006. www. drugfree.org/Files/Full_Teen_Report

55. Boyd CJ, McCabe SE, Cranford JA, Young A. Adolescents' motivations to abuse prescription medications. Pediatrics 2006; 118:2472-2480.

56. Friedman RA. The changing face of teenage drug abuse - the trend toward prescription drugs. $N$ Engl J Med 2006; 354:1448-1450.

57. Gureje O, Von Korff M, Simon GE, Gater R. Persistent pain and well-being: $A$ World Health Organization study in pri- mary care. JAMA 1998; 280:147-151.

58. Federation of State Medical Boards of the United States, Inc. Model Policy for the Use of Controlled Substances for the Treatment of Pain. May 2004. www. fsmb.org/pdf/2004_grpol_Controlled_ Substances.pdf

59. Bennett DS, Simon S, Brennan M, Shoemaker SA. Prevalence and characteristics of breakthrough pain in patients receiving opioids for chronic back pain in pain specialty clinics. J Opioid Manage 2007; 3:101-106.

6o. Davstad I, Stenbacka M, Leifman A, Beck O, Korkmaz S, Romelsjo A. Patterns of illicit drug use and retention in a methadone program: A longitudinal study. J Opioid Manag 2007; 3:27-34.

61. Havens JR, Oser CB, Leukefeld CG. Increasing prevalence of prescription opiate misuse over time among rural probationers. J Opioid Manage 2007; 3:107-112.

62. Chou R, Clark E, Helfand M. Comparative efficacy and safety of long-acting oral opioids for chronic non-cancer pain: A systematic review. J Pain Symptom Manage 2003; 26:1026-1048.

63. Kalso E, Edwards JE, Moore RA, McQuay HJ. Opioids in chronic non-cancer pain: Systematic review of efficacy and safety. Pain 2004; 112:372-380.

64. Bloodworth D. Issues in opioid management. Am J Phys Med Rehabil 2005; $84: S_{42}-S_{55}$.

65. Furlan AD, Sandoval JA, Mailis-Gagnon A, Tunks E. Opioids for chronic noncancer pain: A meta-analysis of effectiveness and side effects. Can Med Assoc J 2006; 174:1589-1594.

66. Eriksen J, Sjogren P, Bruera E, Ekholm 0 , Rasmussen NK. Critical issues on opioids in chronic non-cancer pain. An epidemiological study. Pain 2006; 125:172-179.

67. Kraman P. Drug abuse in America prescription drug diversion. The Council of State Governments. April 2004. www.csg.org.

68. McCaskill C. Oversight Controls in the State's Medicaid Prescription Drug Program, 18 April 2002, Performance Audit Report No. 2002-29, 4 .

69. National Committee Pharmacists Association, NCPA Position Statements, Medicare Reform: JCPP Statement, August 10, 1999. www.ncpanet.org/ about/ncpa_position_statements/ m.shtml
70. Kell M. Monitoring compliance with OxyContin prescriptions in 14,712 patients treated in 127 outpatient pain centers. Pain Med 2005; 6:186-187.

71. Atluri S, Sudarshan G. Evaluation of abnormal urine drug screens among patients with chronic non-malignant pain treated with opioids. Pain Physician 2003; 6:407-409.

72. Webster BS, Verma SK, Gatchel RJ. Relationship between early opioid prescribing for acute occupational low back pain and disability duration, medical costs, subsequent surgery, and late opioid use. Spine 2007; 32:2127-2132.

73. Zacny J, Bigelow G, Compton P, Foley K, Iguchi M, Sannerud C. College on Problems of Drug Dependence task force on prescription opioid non-medical use and abuse (position statement). Drug Alcohol Depend 2003; 69:215-232.

74. Caudill-Slosberg MA, Schwartz LM, Woloshin S. Office visits and analgesic prescriptions for musculoskeletal pain in US: 1980 vs. 2000. Pain 2004; 109:514-519.

75. Vogt MT, Kwoh CK, Cope DK, Osial TA, Culyba M, Starz TW. Analgesic usage for low back pain: Impact on health care costs and service use. Spine 2005; 30:1075-1081.

76. Mahmud MA, Webster BS, Courtney TK, Matz S, Tacci JA, Christiani DC. Clinical management and the duration of disability for work-related low back pain. J Occup Environ Med 2000; 42:1178-1187.

77. Mahowald ML, Singh JA, Majeski P. Opioid use by patients in an orthopedics spine clinic. Arthritis Rheum 2005; 52:312-321.

78. Fanciullo GJ, Ball PA, Girault G, Rose RJ, Hanscom B, Weinstein JN. An observational study on the prevalence and pattern of opioid use in 25,479 patients with spine and radicular pain. Spine 2002; 27:201-205.

79. Fillingim RB, Doleys DM, Edwards RR, Lowery D. Clinical characteristics of chronic back pain as a function of gender and oral opioid use. Spine 2003; 28:143-150.

8o. Deyo RA, Bass JE, Walsh NE, Schoenfeld LS, Ramamurthy S. Prognostic variability among chronic pain patients: Implications for study design, interpretation, and reporting. Arch Phys Med Rehabil 1988; 69:174-178.

81. Breckenridge J, Clark JD. Patient characteristics associated with opioid versus nonsteroidal anti-inflammatory 
drug management of chronic low back pain. J Pain 2003; 4:344-350.

82. Reid MC, Engles-Horton LL, Weber MB, Kerns RD, Rogers EL, O'Connor PG. Use of opioid medications for chronic noncancer pain syndromes in primary care. J Gen Intern Med 2002; 17:173-179.

83. Polatin PB, Kinney RK, Gatchel RJ, Lillo E, Mayer TG. Psychiatric illness and chronic low-back pain. The mind and the spine-which goes first? Spine 1993; 18:66-71.

84. Bramley-Moore SR, Wodak AD, Day RO, Lauchlan RL. Patterns of analgesic prescribing for patients with chronic nonmalignant pain in NSW. Aust J Hosp Pharm 1998; 28:83-88.

85. Ready LB, Sarkis E, Turner JA. Self-reported vs. actual use of medications in chronic pain patients. Pain 1982; 12:285-294.

86. Maxwell JC. Trends in the Abuse of Prescription Drugs. Gulf Goast ATTC, Austin Treatment, 2006.

87. Wiedemer NL, Harden PS, Arndt IO,
Gallagher RM. The opioid renewal clinic: A primary care, managed approach to opioid therapy in chronic pain patients at risk for substance abuse. Pain Med 2007; 8:573-584.

88. Office of Applied Studies (2007) Changes in Prevalence Rates of Drug Use between 2002-2003 and 2004 2005 among states. Rockville, MD: Substance Abuse and Mental Health Administration. www.oas.samhsa.gov/ StateChanges/3trends.doc

89. The National Center on Addiction and Substance Abuse. National survey of American attitudes on substance abuse XII: Teens and parents. August 2007. www.casacolumbia.org/abso lutenm/articlefiles/380-2007\%20Teen $\% 20$ Survey\%20XII.pdf

90. Luo X, Pietrobon R, Hey L. Patterns and trends in opioid use among individuals with back pain in the United States. Spine 2004; 29:884-891.

91. White AG, Birnbaum HG, Mareva MN, Daher M, Vallow S, Schein J, Katz N. Di- rect costs of opioid abuse in an insured population in the United States. J Manag Care Pharm 2005; 11:469-479.

92. Substance Abuse and Mental Health Services Administration, Office of Applied Studies (2006). Opiate-related drug misuse deaths in six states: 2003. The New DAWN Report, issue 19.

93. Strom KJ, Wong L, Weimer BJ, Ancheta J, Rachal V. NFLIS Special Report: Controlled Prescription Drugs, 2001-2005. Washington DC, U.S. Drug Enforcement Administration, 2006. www.utex as.edu/research/cswr/gcattc/docu ments/PrescriptionTrends_Web.pdf

94. U.S. Food and Drug Administration, Center for Drug Evaluation and Research. FDA Public Health Advisory. Methadone Use for Pain Control May Result in Death and Life-threatening Changes in Breathing and Heartbeat. November 27, 2006. www.fda.gov/ cder/drug/advisory/methadone.htm 